\title{
Extortion, intuition, and the dark side of reciprocity ${ }^{1}$
}

\author{
Regan M. Bernhard \& Fiery Cushman \\ Harvard University
}

\begin{abstract}
Extortion occurs when one person uses some combination of threats and promises to extract an unfair share of benefits from another. Although extortion is a pervasive feature of human interaction, it has received relatively little attention in psychological research. But, we argue, extortion is structured quite similarly to far better-studied "reciprocal" social behaviors, such as conditional cooperation and retributive punishment. All of these strategies function to elicit some desirable behavior from a social partner and do so by constructing conditional incentives. The main difference is that the desired behavioral response is an unfair or unjust allocation of resources during extortion, whereas it is typically assumed to be a fair or just distribution of resources in studies of reciprocal cooperation and punishment. Thus, we propose that a common set of psychological mechanisms may render these strategies successful. We know from prior work that prosocial forms of reciprocity often work best when implemented inflexibly and intuitively, rather than deliberatively. This both affords long-term commitment to the reciprocal strategy, and also signals this commitment to social partners. We argue that, for the same reasons, extortion is likely to depend largely upon inflexible, intuitive psychological processes. Several existing lines of circumstantial evidence support this conjecture.
\end{abstract}

\section{Introduction}

Extortion sounds exotic, but it happens all the time. It happens whenever one person constructs incentives - whether carrots or sticks - to extract an unfair share of benefits from another. A mob boss who threatens to break the windows of shop owners who don't pay a tax is extortionate. Happily, for most readers, this variety of extortion is rarely experienced. But a toddler who throws tantrums when he doesn't get candy is extorting his parents, and a boss who gives plum promotions to those who work uncompensated hours is extorting her employees. An airline passenger who throws a loud fit until they get a better seat is extorting the flight crew. A cabbie who tacks on an extra fee when he's your only option late at night is extorting you.

Regrettably, these kinds of behaviors are a basic thread in the fabric of human social interaction. It is remarkable, then, how little we understand about their psychological basis. It would take a small library to house the academic research on the better angels of our nature: prosociality, cooperation, fairness, and the like. The research on their fallen cousin, extortion, would probably fit in a manila envelope.

Our goal is to stretch the envelope by proposing a mechanistic account of extortionate behavior. To do this, we draw inspiration from an unlikely but powerful source: the literature on prosociality. We argue that extortion is not quite the antithesis of prosocial behavior, but more like its evil twin - a set of behaviors that exploit common mechanisms towards an altered goal. Thus, we can better understand some antisocial behaviors by studying the structure of prosocial ones.

This argument has two parts. First, extortion and prosociality face a common set of challenges. Each of them pays short-term costs in order to elicit from social partners behaviors of long-term value. Moreover, in order to succeed, each of them must convince social partners that they are truly committed-either to giving a fair deal (in the case of prosociality), or to insisting on an unfair one (in the case of extortion).

Given that successful extortion and prosociality face common challenges, then, the second part of our

\footnotetext{
${ }^{1}$ Correspondence concerning this article should be addressed to Regan M. Bernhard, Ph.D., Program in Cognitive Science, Dartmouth College, Winifred Raven House 107, HB 6256, Hanover, NH, 03755, United States. Email: regan.bernhard@gmail.com. Draft version 3.0,6/1/22. This paper has not been peer reviewed. Please do not copy or cite without author's permission.
} 
argument follows naturally: They solve these challenges in a common way. Specifically, each of them relies on psychological mechanisms that are quick and inflexible-on processes like instinct and intuition. Indeed, this has been one of the central ideas in recent research on prosocial behavior: It is our default, automatic, or intuitive response (Zaki \& Mitchell, 2013; Rand et al., 2014; Lotz, 2015; Levine, Barasch, Rand, Berman \& Small, 2018). We propose that the very same insight can be productively applied to extortionate behavior.

Thus, while our principal aim is to understand the psychological mechanisms that make extortion work, the argument that we develop invites a unifying perspective on several kinds of social behavior: prosociality, extortion, and also retributive punishment. We propose that these behaviors share a common purpose (to change others' behavior, albeit in different ways). They face a common set of challenges in order to succeed, and thus are likely to have evolved (biologically or culturally) similar designs. As a corollary then, all three of these social behaviors can be understood as species of a common genus, more alike than we have tended to acknowledge-or perhaps care to admit.

\section{Extortion in practice}

In extortionate relationships one individual is able to control her partner's behavior by establishing a set of contingent responses, and does so in order to elicit unfair and personally advantageous outcomes (Press \& Dyson, 2012; Stewart \& Plotkin, 2012). By responding with harsh punishment when her partner isn't cooperative, and mild rewards when her partner is cooperative, an extorter is able to create conditions in which she will always do better than her partner, yet it is in her partner's own best interest to be fully compliant (Becks \& Milinski, 2019; Hilbe, Hagel, \& Milinski, 2016; Press \& Dyson, 2012).

Reliance on "contingent responses" is the first essential part of this definition of extortion. In other words, extortion involves a strategy of the kind, "Do as I say, or else". There are, of course, other ways to act unfairly. A litterer who leaves their trash for others to clean up is acting unfairly, but not extortionately, because he makes no attempt to control others' behavior through contingent responses ("clean up my litter or else..."). In contrast, consider a plumber who charges exorbitant prices for his services by saying, "Pay my price or else I'll never take a job for you again" (or, in the manner of the mob boss: “... or else I'll break your legs"). He extracts a personally advantageous outcome by adopting a contingent response to his partner's behavior.
Extraction of an unfair resource distribution is the second key part of this definition. Yet, while behavioral scientists and ordinary people have an operational understanding of fairness, it is notoriously difficult to define. We do not attempt to offer a precise definition here, although there are promising candidates in the literature (e.g. Baumard \& Boyer, 2013; Fehr \& Schmidt, 1999; Kahneman, Knetch, \& Thaler, 1986.). Instead, we rely on the fact that people know it when they see it. For our purposes, then, extortion involves an attempt to attain a resource allocation that is more advantageous to the extorterand more costly to the target of extortion-than prevailing norms dictate as morally appropriate. Thus, as we define it, extortion is always an antisocial act.

Extortion, in this sense, is therefore closely related to coercion, in which one individual uses the threat of aggression to force another player's behavior (Clutton-Brock \& Parker, 1995; Raihani, Thornton, \& Bshary, 2012). If coercion is used to extract an unfair resource distribution, this is also a case of extortion.

However, there are key cases in which the two come apart. First, in the case of coercion, the target would always be better off if they were able to avoid the relationship altogether. In the case of extortion, this is sometimes true: The shopkeeper would be better off if he could avoid interacting with the mob boss all together. But extortionate relationships can also be positive sum: Both the extorter and the victim receive benefits from the relationship, the extorter simply receives more (Hilbe, Nowak, \& Sigmund, 2013; Press \& Dyson, 2012; Stewart \& Plotkin, 2012; Stewart \& Plotkin, 2013). If your plumber charges an unfair price, you may still be better off paying that price than going permanently without plumbing services. As this example illustrates, positive-sum extortion might be most prevalent when there is little or no partner choice available, as in the case of a monopoly (Hilbe, Hagel, \& Milinski, 2016). This example also departs from the standard definition of coercion in that the plumber is not threatening aggression. What he offers is a "gain" (i.e., his ongoing services) contingent on an unfair price, not a "loss" contingent on non-compliance.

The second case where extortion and coercion diverge is when coercion is used to enforce fair resource distributions. A parent can, for example, coerce her child into playing nicely with his sister by threatening punishment if he doesn't. Extortion on the other hand, always seeks to elicit unfair outcomes that are advantageous to the extorter.

Despite the differences between coercion and extortion, they share the property of using incentives to manipulate a partner's behavior to obtain desired outcomes, and consequently, many of the arguments 
we make here likely apply to coercion as well as extortion.

Although our goal is to understand the psychological mechanisms that support extortion, not to give a comprehensive review of extortionate behavior in ordinary human life, it is useful to reflect on its prevalence across history and cultures, including in contemporary, industrialized, and democratic societies.

One recurring context that promotes extortion is in social category-based divisions of labor, which can be understood as a complementary coordination problem (O'Connor, 2019). It is often the case that category membership is used to determine which party takes which action (McElreath, Boyd, \& Richerson, 2003). Consider, for example, traditional gender roles where men hunt or plow (or in contemporary society, work) and women care for the children. A gendered division of labor efficiently solves this who-does-what coordination problem. Moreover, everyone is better off if coordination is successful because the necessary goals of acquiring food and raising offspring are both achieved. Nevertheless, this division of labor results in inequitable access to resources - the resources yielded from hunting or working far exceeded the resources yielded from child-rearing. As a consequence of this persistent inequitable access to resources, a convention of pervasive inequity may develop (O'Connor, 2019; Bruner \& O'Connor, 2016; Ridgeway, 2011). The more powerful group has the motivation and capacity to continue to enforce an inequitable division of resources and the less powerful group has learned that they are better off accepting what they can, rather than allowing coordination to fail (Nash, 1953).

The example described above is captured by the Nash demand game (Nash, 1950). Past work has found that whenever groups are added to such a bargaining problem, conventions of inequity or discrimination are likely to emerge (Axtell, Epstein, \& Young, 2001; Bowles \& Naidu, 2006; Poza et al., 2011), particularly when one group is the majority (Bruner, 2019), has less to lose if the collaboration fails (Binmore et al., 1989; Binmore et al., 1991), has more initial resources or background payoffs (Bruner \& O'Connor, 2016), or has additional outside options (Harsanyi \& Selton, 1998). This phenomenon has been used to explain modern-day social stratification (Hoffmann, 2006; Smith \& Choi, 2007), racial inequity (Stewart, 2010), and gender inequity (Ridgeway, 2011). It has also been studied in the context of academic relationships in which collaboration is often required for success (Bruner \& O'Connor, 2016). The hierarchical structure of academic culture makes inequitable bargaining, and consequently extortive relationships, highly likely. As a concrete example, consider who arrives first to academic meetings. The Dean is never kept waiting, but the undergraduate research assistant may rarely have a meeting with her supervisor that starts on time. Here the supervisor is able to extort the research assistant-he can enforce an inequitable division of resources (in this case time), yet she is better off waiting than not meeting with him at all.

Thus, while we like to think of extortion as constrained to the behavior of a particularly malicious few, it may instead be an integral part of our social fabric-occurring particularly frequently when individuals from different social categories must coordinate action or divide resources. Given the prevalence of extortionate relationships in our everyday lives, it would be useful to understand the psychological mechanisms that support it. We turn now to addressing that question.

\section{The logic of extortion}

As described above, extortionate strategies are most clearly identifiable when there is an asymmetry in power (Nikiforakis, Oechssler, \& Shah, 2014; Phillips, 2018). In these cases, individuals with more authority, money, status, information, or power, take advantage of those who have no choice but to capitulate to their demands. Examples range from pharmaceutical executives who overcharge for lifesaving drugs over which their companies have monopolies (Pollack, 2015) to domestic abusers who maintain captivity over their partners, whether by force or illusion (Barnett, 2001). Experimental research confirms that extortion emerges when people have a clear power advantage (Andrighetto \& Grieco, 2020; Bolle, Breitmoser, \& Schlächter, 2011; Hilbe, Hagel, \& Milinski, 2016; Nikiforakis, Oechssler, \& Shah, 2014).

Importantly, however, extortion can also persist in the absence of a power asymmetry. This has been demonstrated with the recent formalization of extortionate strategies in the iterated prisoner's dilemma (PD). In particular, a class of strategies, known as zero determinant (ZD) strategies, enables the enforcement of a linear relationship between the ZD player's payoffs and those of her partner (Hilbe, Sigmund, \& Nowak, 2013; Press \& Dyson, 2012; Stewart \& Plotkin, 2012; Stewart \& Plotkin, 2013) by cooperating with a fixed probability conditioned on the outcome of the prior round. While nonextortionate ZD strategies can be fair, or even generous, extortionate ZD strategies ensure that the ZD player's payoff is always equal to or better than her partner's. The extortionate ZD player cooperates sufficiently often enough to ensure that her partner's best option is to be fully cooperative, but she 
cooperates less often than her partner, thus ensuring a relative advantage. Critically, the extortionate ZD player is able to achieve this advantage despite the fact that the iterated prisoner's dilemma is a symmetrical game where both players are operating with the same payoff structure (Axelrod, 1980).

There is some evidence that extortionate ZD-like strategies can emerge in the lab. So far, however, this has only been demonstrated under conditions of asymmetric power (Andrighetto \& Grieco, 2020; Bolle, Breitmoser, \& Schlächter, 2011; Hilbe, Hagel, \& Milinski, 2016; Nikiforakis, Oechssler, \& Shah, 2014) or when establishing a competitive advantage is incentivized (Becks \& Milinski, 2019; Milinski, Hilbe, Semmann, Sommerfeld, \& Marotzke, 2016). For example, in one recent study participants played an adapted version of an iterated PD in which one player had the advantage of getting to choose which two out of three potential partners she would play with at any given time (Hilbe, Hagel, \& Milinski, 2016). They found that this power asymmetry sometimes evoked extortionate behavior from the more powerful player. Specifically, these extortionate players cooperated less than their partners, had higher payoffs than the less powerful players (or other players in a control condition without a power asymmetry), and the less powerful players increased their rates of cooperation over time, independent of whether or not the powerful player cooperated on the previous round. Consistent with the model of an extortionate ZD player, these powerful players were able to set a linear relationship between their partner's and their own payoffs.

This case study of extortionate ZD strategies shares two key features with more ordinary cases of extortion like bullies and mob bosses. First, they are both conditional strategies. The likelihood of a ZD player engaging in cooperation depends on her partner's behavior in the previous round (Press \& Dyson, 2012). Likewise, the mob boss smashes the windows of the local corner store in response to the shopkeeper's resistance to paying for his protection. Second, both function to control their partners' behavior to produce unfair outcomes. The extortionate ZD player unilaterally sets her partner's payoffs so that she always performs as well or better than her partner (Press \& Dyson, 2012). Likewise, the mob boss uses threats and violence to pad his own pockets. His goal is not to divide resources evenly or prosocially, but to gain a relative advantage by hoarding them.

We argue that strategies with these featuresthose that use conditional action (i.e., a form of reciprocity) to control a partner's behavior-belong to a coherent general class, which is a useful target for theorizing. We call these conditional control strategies. They include extortion, reciprocal cooperation, and punishment (or at least some cases of it; see Raihani \& Bshary, 2019). Critically, all conditional control strategies, including extortionate strategies, share these key features, and consequently, face a common set of challenges. We suggest that they may share common solutions to those challenges as well. Therefore, we can use well-studied conditional control strategies (e.g., reciprocal cooperation and punishment) as a model for the psychological mechanisms that likely support extortionate strategies.

\section{Extortion as a conditional control strategy}

What, exactly, is a conditional control strategy? By "conditional", we mean strategies in which a person's behavior (for instance, to cooperate, defect, help, harm, reward, or punish) depends in part on the history of play in an iterated game (Bshary \& Bergmüller, 2007; Dugatkin, 1997; Gross \& Repka, 1998; Nowak, 2006; Nowak \& Sigmund, 1990; Smith, 1979). A classic example is tit-for-tat (TFT), a reciprocal strategy in the iterated prisoner's dilemma in which a player conditions their move in the present round on their partner's move in the last round: cooperation for cooperation, defection for defection (Axelrod \& Hamilton, 1981). This contrasts with unconditional strategies, such as "always cooperate" or "always defect", which do not depend on the history of play. The possibility of a conditional strategy is not restricted, of course, to the iterated PD; it arises in any repeated interaction (Sigmund \& Nowak, 1999).

Extortionate strategies are always conditional, in that the extorter's behavior depends on their partner's history of cooperation. This is true both in the case of modeled extortionate ZD strategies, which are conditioned upon both the ZD player's and the partner's behavior in the previous round (He, Geng, Shen, \& Shi, 2020; Hilbe, Chaterjee, \& Nowak, 2018; Hilbe, Nowak, \& Sigmund, 2013; Press \& Dyson, 2012; Stewart \& Plotkin, 2012; Wang et al., 2016), and in extortionate behavior elicited in the lab (Becks \& Milinski, 2019; Hilbe, Hagel, \& Milinski, 2016; Milinski, Hilbe, Semmann, Sommerfeld, \& Marotzke, 2016). Likewise, it is also true in cases of real-world extortion. A mob boss must ramp up or ease down the pressure on the shopkeeper depending on the shop keeper's willingness to pay his tithes. Without this contingency, the shopkeeper has no incentive to comply.

By "control", we mean those strategies that function to elicit a specific behavioral outcome in a social partner-for instance, cooperating more, or desisting from harm (Bshary \& Grutter, 2002; Martin \& Cushman, 2015; Schino \& Aureli, 2017). Consider again the example of TFT in the iterated PD. We can regard it as a control strategy that functions to elicit 
cooperation on the part of the social partner (Axelrod \& Hamilton, 1981). The reward of "giving" cooperation is conditional upon "receiving" cooperation. When we say that a control strategy functions to elicit a particular behavioral response from social partners, we do not mean to imply that the agent employing this strategy explicitly represents its function. That is possible, but not necessary; rather, it could result from a variety of adaptive processes such as biological or cultural evolution, or reward learning, in addition to reasoning.

We intend "control" to mean changing a specific social partner's behavior within their lifetime (Clutton-Brock \& Parker, 1995), due to their learning (or "facultative adjustment"; Gardner \& West, 2004). This contrasts with the role that conditional strategies can play in shaping evolutionary dynamics, enhancing or diminishing the fitness of other static strategies (i.e., partner strategies incapable of learning; Axelrod \& Hamilton, 1981; Nowak, 2006). It also contrasts with the role that conditional strategies can play in establishing an individual as a "valuable partner" (i.e., in models of the evolution of cooperation by partner choice; Bull \& Rice, 1991; Noe, Schaik, \& Hoof, 2010; Roberts, 1998). In the literature on the evolution of cooperation there is extensive treatment of the evolutionary dynamics induced by conditional strategies (see Nowak, Tarnita, \& Antal, 2010, for a review). Although there is relatively less research on the way that individuals can learn and adjust their behavior in response to conditional strategies within their lifetime, this topic has been studied through several complementary lenses (Fudenberg, Drew, Levine, \& Levine, 1998; Gardner \& West, 2004; Cushman \& Morris, 2015; Clutton-Brock \& Parker, 1995; Macy \& Flache, 2002). Here, we build on this latter approach.

\footnotetext{
${ }^{2}$ While at first blush, defection in the PD has the flavor of negative reciprocity, or punishment, the payoff structure of the PD makes defection payoff maximizing, not costly. While some have argued that punishment does not require
}

Although TFT in the iterated PD is a classic example of a conditional control strategy, the full space of conditional control strategies is larger. This can be illustrated by highlighting two potential alterations to TFT. First, while TFT uses both reciprocal cooperation and reciprocal defection (Axelrod \& Hamilton, 1981), TFT is most naturally construed as an instance of "positive reciprocity": It creates value for a social partner contingent upon their creating social value for you (Trivers, 1971). This differs from "negative reciprocity", in which (as we use the term ${ }^{2}$ ) a player imposes a cost on a social partner (at a cost to themselves) contingent upon their partner's undesirable behavior, rather than bestowing a benefit on them contingent upon their desired behavior (Bshary \& Bergmüller, 2008; Clutton-Brock \& Parker, 1995; Raihani, Thornton, \& Bshary, 2012; Raihani \& Bshary, 2019). Like positive reciprocity, negative reciprocity can be used as a conditional control strategy.

Second, TFT functions to elicit a fair division of resources (Axelrod \& Hamilton, 1981). In other words, it only demands from the partner what it offers in return. But, both positive and negative reciprocity can also be used to elicit unfair divisions of resources. In the present paper, we use this distinction (between reciprocity used to elicit fair divisions of resources vs. those used to elicit unfair divisions of resources) to differentiate between prosocial and extortionate strategies. Then, by altering both the desired distribution and the type of reciprocity used to achieve that distribution, we obtain a simple taxonomy of conditional control strategies (Figure 1). We next discuss the two dimensions of this taxonomy in more detail. the punisher to incur costs (e.g. Boyd \& Richerson, 1992; Chernyak et al., 2019; Nakao \& Machery, 2012), which more closely reflects defection in the PD, we define negative reciprocity here as a costly behavior. 


\section{Contingency type}

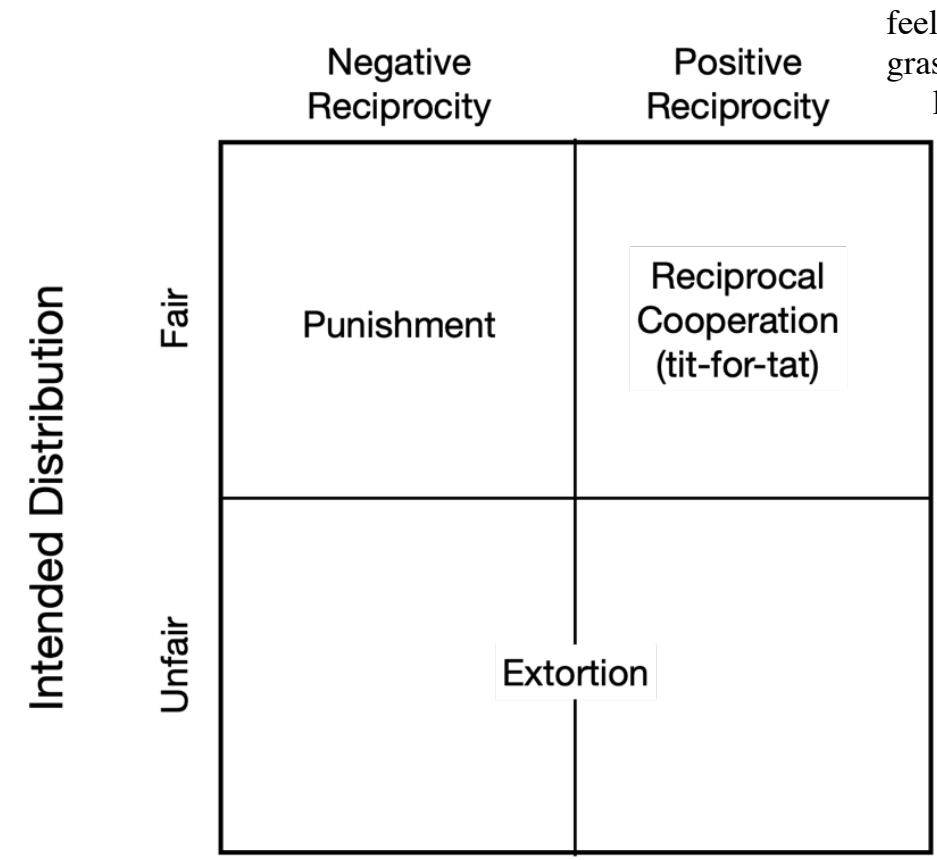

The distinction between positive and negative reciprocity-i.e., reward and punishment-sometimes feels more slippery the more firmly we attempt to grasp it. In the iterated prisoner's dilemma, a strategy

like TFT can be viewed as "cooperation conditional upon cooperation", or as "defection conditional upon defection" (Chernyak et al., 2019; Bshary \& Bergmüller, 2007). The former sounds like positive reciprocity, while the latter sounds like negative reciprocity. But, of course, they are just alternative descriptions of the same strategy. In order to set this distinction on firmer ground, we construe negative reciprocity not just in terms of the strategy, but also in terms of the specific payoff structure of the game. We describe TFT as an instance of positive reciprocity because it is deployed in a game with a payoff matrix that allows for value creationincurring a small personal cost to impart a larger benefit to the other player. Other games, such as the ultimatum game, involve different payoff matrices that allow for value destructionincurring a personal cost to impose a cost on the other player (Guth, Schmittberger, \& Schwarze,

Figure 1. A taxonomy of conditional control strategies. Both prosocial strategies (those that seek a fair distribution of resources) and extortionate strategies (those that seek an unfair distribution of resources) can use either positive or negative reciprocity to achieve their desired ends.

\subsection{Positive vs. negative reciprocity}

We begin by considering the distinction between negative and positive reciprocity. Punishment is a classic example of negative reciprocity (Raihani, Thornton, \& Bshary, 2012). For instance, a person may adopt the policy of punching anybody who insults them. In many cases punishment is an important tool to stabilize cooperative behavior (e.g. Boyd \& Richerson, 1992; Fehr \& Gachter, 2000). In fact, the enforcement of cooperative behavior by punishment is believed to have evolved independently across many structural levels in biological systems, from genomes to humans (e.g. Årgen, Davies, \& Foster, 2019; Bshary \& Grutter, 2005; Cant, 2011; Clutton-Brock \& Parker, 1995; Gardner \& West, 2004; Jensen, 2010; Melis \& Semman, 2010). In these cases, where negative reciprocity enforces prosocial norms, it can itself be regarded as a prosocial behavior. Of course, it is always a harmful behavior, at least in the restricted sense that it imposes a direct and immediate cost upon its target. But even harmful behaviors can be prosocial (Fehr, Fischbacher, \& Gächter, 2002; Gintis, 2000; Gintis et al., 2008) - just think of Batman socking the Joker. As we will soon see however, many other uses of negative reciprocity are decidedly less prosocial.
1982; Thaler, 1988). As we use the term (and following others), a conditional strategy that exploits value destruction involves negative reciprocity (see also Raihani \& Bshary, 2012). A conditional strategy that employs value creation involves positive reciprocity. Thus, the opportunity to employ positive and/or negative reciprocity depends on the payoff matrix of the game in question. Some games afford both opportunities (Dreber, Rand, Fudenberg, \& Nowak, 2008) and, presumably, so do most real-world human interactions (Raihani \& Bshary, 2011).

\subsection{Fair vs. unfair distribution}

The second alteration that we consider to TFT concerns not the payoff structure of the game, but the goals of a player. In TFT, the conditional strategy attempts to impose an equitable, fair, or prosocial, division of resources. Likewise, in many instances, negative reciprocity is also deployed in service of creating more fair outcomes (e.g., Fehr \& Fischbacher, 2004; Fehr \& Gächter, 2003; Fehr \& Schmidt, 1999; FeldmanHall, Sokol-Hessner, Van Bavel, \& Phelps, 2014; Güth, Schmittberger, \& Schwarze, 1982; Henrich et al., 2010; Henrich et al., 2006; Mathew \& Boyd, 2011; Raihani, Thornton, \& Bshary, 2012; Thaler, 1988). But we can alter the strategy so that it becomes extortionate, attempting to create unfair resource allocations. Whether extortion involves positive or negative reciprocity, it functions to create an unequal balance of resource exchange that favors the extorter (Hilbe, Chaterjee, \& Nowak, 2018). For 
instance, consider the use of a "fickle" strategy of positive reciprocity that demands pure cooperation on the part of social partners, but offers incomplete cooperation in return. If partial cooperation is the best outcome the partner can hope for, this strategy can succeed in eliciting an unbalanced allocation of resources. The adoption of a prosocial versus extortionate strategy need not depend on any change to the structure of the payoff matrix. For instance, both prosocial and extortionate strategies can be employed in the iterated PD (Press \& Dyson, 2012).

\subsection{Summary}

The prototypical cases of extortion that come most easily to mind tend to rely on negative reciprocity (i.e., threats) rather than positive reciprocity. Consider again the mob boss who threatens the property or wellbeing of local shopkeepers unless they offer monthly tithes. This is an extortionate strategy: The goal of the boss is not to achieve a fair distribution of resources, but instead to create a personal advantage. It also depends not on positive reciprocity (creating value for those who tithe) but instead on negative reciprocity (destroying value for those who don't). If the mob boss instead threatened the property of local shopkeepers unless they paid fair wages and adhered to local labor laws, his use of negative reciprocity would no longer be extortionate, it would be prosocial. (And, in that case, we would no longer call him the "Don", but rather the Attorney General.)

As this example illustrates, the distinctions between positive and negative reciprocity, and between prosocial and extortionate behavior, are important. But, they should not obscure central underlying similarities. First, all of these strategies are conditional: The behavior of an individual using one of these strategies in a given moment depends on her partner's earlier behavior. Second, they function for "control": Each of these strategies uses its conditional form to attempt to shape other players' future behavior to achieve a desired outcome.

As we describe below, successfully implementing any conditional control strategy faces several challenges.

\section{Extortion faces the same challenges as other conditional control strategies}

In order to understand the psychological mechanisms that support extortionate behavior, we must understand its design (Marr \& Poggio, 1976): What is it for, what challenges does it face, and how can these be overcome? We argue that all conditional control strategies face a common set of challenges, and that these challenges, and their solutions, have been well-studied in the case of prosocial and punitive behavior. This provides a promising blueprint for understanding the design of extortion.

What are the challenges? There is an idealized setting in which conditional control strategies can achieve their goals quickly and reliably: rational actors, operating with full information, followed by perfect execution of the rational strategy. Of course, this setting involves several unrealistic assumptions. First, in the real world, agents are unaware of each other's strategies and must infer them by learning (Cramerer, 2003; Erev \& Roth, 1998; Fudenberg, Drew, Levine, \& Levine, 1988; Mookherjee \& Sopher, 1994; Walker \& Wooders, 2001). Additionally, they may have to learn an appropriate response adaptively and gradually, rather than computing the rational response instantly. Second, this idealization assumes that a conditional control strategy is implemented flawlessly and inflexibly (Hilbe, Chatterjee, \& Nowak, 2018; Press \& Dyson, 2012). Yet realistically, agents may implement conditional control policies imperfectly, or may choose to abandon a conditional control strategy entirely if it seems not to be working.

These real-world challenges are essential to our analysis. Together, they establish a "critical period" during which the success of a conditional control strategy is uncertain. During this period, the player implementing the control strategy is paying costs to attempt to change her partner's behavior but is not yet recouping these costs while she waits for her partner to adopt the intended behavioral response. Thus, during this period she may be tempted to abandon the control strategy. What's worse, her opponent may attempt to exploit this temptation by "holding out"-resisting the preferred resource distribution of the control strategist in order to test her resolve and see whether she may abandon her approach (Morris, MacGlashan, Littman, \& Cushman, 2017).

From these observations we can distill two essential challenges for conditional control strategies: An intertemporal challenge associated with acquiring the strategy in the first place and then sticking to it during the costly critical period, and the communicative challenge of ensuring that the social partner both understands the conditional control strategy being adopted, and also believes that the control strategist will not back down from it.

The intertemporal challenge can take two different forms. First, consider the possibility that a person might learn to adopt a conditional control strategy by instrumental learning -i.e., trial-and-error learning. Suppose they have been trying out different ways to negotiate social relationships-could they gradually discover that just the right mixture of carrots and sticks can eventually shape their social partners' 
behaviors in desirable ways? Although possible, this learning process faces significant obstacles. Conditional control strategies usually involve paying immediate costs (e.g., the cost of cooperation, or of punishment), whereas their gains are delayed (i.e., dependent on the eventual behavioral change of the social partner; West, Griffin, \& Gardner, 2007; Bshary \& Bergmüller, 2008). Early in the trial-and-error process then, a learning algorithm may falsely conclude that the costs outweigh the benefits (Morris, MacGlashan, Littman, \& Cushman, 2017).

On the other hand, if we assume that conditional control strategies are implemented by deliberationthat is, motivated by an explicit representation of their long-run prospects of reward-the intertemporal challenge takes a different form. For a variety of reasons, people typically exhibit temporal discounting-i.e., weighting short-term rewards more strongly than long-run rewards in decision-making (Green, Fry, Myerson, 1994). To the extent that a person deliberately chooses a conditional control strategy, they must therefore overcome the temptation to abandon this strategy for short-term gain. Here, the intertemporal challenge manifests in motivation, rather than in learning.

Turning next to the communicative challenge, a conditional control strategy must also successfully induce behavioral change in social partners. For instance, for an extorter to control her partner's behavior, she must effectively convince her partner that she is sufficiently committed to the extortionate strategy and that her partner's best option is to fully comply with her demands (Frank, 1988; Press \& Dyson, 2012). More broadly, conditional control strategies require that social partners eventually adapt their behavior to the best response-in other words, acceding to control. But if conditional control strategies differ in their degree of "commitment"i.e., if there is variability in the inflexibility with which the strategy is pursued in the face of a resistant social partner-then there is an incentive for social partners to test limits, ascertaining whether they achieve a superior long-run payoff by refusing to accede. In these circumstances, a conditional control strategy will be more successful to the extent that it can send a

\footnotetext{
${ }^{3}$ Press and Dyson (2012) refer to these as "evolutionary" players. Such players might respond to their partners' behavior by using a fixed, innate strategy subject to intergenerational selection, or they might adapt to maximize payoffs via model-free learning.

${ }^{4}$ Following past work (Press \& Dyson 2012), our discussion assumes that the extorter is committed to a rigid (i.e., inflexible) strategy to which the target of extortion flexibly best-responds. It is interesting to ask what would
}

credible signal to the social partner that it is truly, inflexibly committed (Frank, 1988; Hirshleifer, 1987; Schelling, 1960).

The intertemporal and communicative challenges faced by conditional control strategies are well characterized in the model of extortionate zero determinant strategies (Press \& Dyson, 2012). If an extortionate ZD player is engaging with an opponent who adapts to her extortionate behavior, by maximizing his own payoff without planning over an explicit model of the ZD player's strategy, then the opponent's best response will generate the ZD player's preferred resource distribution ${ }^{3}$. If, on the other hand, the opponent is "sentient"-i.e., possesses and plans over a model of the ZD player's approach-then he may attempt to punish the extortionate ZD player, seeking to shift her strategy and elicit fair play. However, there is one way an extortionate ZD player can dominate even a sentient partner: if the extortionate ZD player is unresponsive to her sentient partner's punishments and can convince her partner of this fact. In this case the partner's sentience grants him no advantage.

In other words, for the ZD player to be successful against a sentient partner, she must achieve the same two goals faced by an individual engaging in any conditional control strategy. First, the extortionate ZD player must establish and remain committed to her strategy in the face of short-term costs. In this case these costs come from her sentient partner's early resistance to her extortionate behavior-for example, defection in response to defection. Second, the extortionate ZD player must clearly signal to her partner that her strategy is fixed. When the extortionate ZD player is effectively able to do these two things, her partner should learn that ongoing attempts to change the extorter's behavior will be costly and futile. Consequently, he should act just as the evolutionary player does, maximizing his fitness by fully cooperating. In this case, the extortionate ZD player dominates her partner not because of a structural asymmetry inherent in the game, but because of an asymmetry in the "rigidity" or "flexibility" of their respective strategies (see also Morris, MacGlashan, Littman, \& Cushman 2017) ${ }^{4}$.

occur if we relaxed this assumption, allowing both players to evolve strategies of varying degrees of rigidity vs. flexibility. Morris et al. (2017) explore this kind of evolutionary dynamic in the specific case of antisocial behavior followed by retributive punishment (i.e., negative reciprocity). The observed equilibrium tends to be flexibility in antisocial behavior and rigidity in retributive punishment, but the opposite equilibria can be stable under certain parameter regimes. Two more general conclusions of their work are applicable to the evolution of extortion. 
The advantage of observable strategic intransigence has been likewise described by Nash, who suggested that threats in bargaining relationships are only successful if one is "compelled to carry out his threat" (Nash, 1953, pg. 130). Schelling (1960) and Frank (1988) have similarly argued that enduring costs to engage in a cooperative strategy can be particularly beneficial as it convinces one's partners of strategic commitment.

We can already begin to see the rough shape required of any cognitive mechanism that will overcome these intertemporal and communicative challenges. It must be inflexibly committed to the conditional control strategy, rather than relying on the contingent flexibility of instrumental learning and decision-making. And, it must exhibit signature properties of this inflexibility that can be perceived by social partners.

\section{Intuition as a solution}

Broadly speaking, there is a certain kind of psychological mechanism that can successfully toughout short-term costs for long-term benefits. It includes emotions, instincts (i.e., innate or genetically determined behaviors), reflexes, and habits - the kinds of non-deliberative processes that are sometimes described as "intuition" (Frank, 1988; Hirshleifer, 1987). As we use the term, intuition refers to a broad style of thought characterized by computational efficiency but inflexibility. Deliberation, in contrast, is computationally demanding but flexible (see Kahneman, 2011, for a review). Following prior work (Bear \& Rand, 2016), we focus on intuitions inherited through biological or cultural evolution (as opposed to those that are learned, for instance). While the stubborn inflexibility of intuitions is disadvantageous for many non-social tasks (see Evans, 2003, for a review), it is precisely this inflexibility that makes them ideally suited for implementing conditional control strategies.

The inflexibility of intuitive processes address both of the key challenges we described above: They motivate and commit us to persisting in such behavior despite the immediate costs (Frank, 1988; Bear \& Rand, 2016), and they serve as a reliable signal to others that we are engaging in a fixed strategy (Ames \& Johar, 2009; Chritcher, Inbar, \& Pizarro, 2012; Everett, Pizarro, \& Crockett, 2016; Hilbe, Hoffman, \&

First, consistent with Press \& Dyson (2012), they find that inflexible behavior can allow a player to attain its preferred behavioral equilibrium in a game. Second, their work suggests that the player who evolves an inflexible behavior tends to be the one for whom flexibility-i.e., successfully learning an optimal policy-is harder. Thus, we might
Nowak, 2015; Hoffman, Yoeli, \& Nowak, 2015; Jordan, Hoffman, Nowak, \& Rand, 2016; Monin, Pizarro, \& Beer, 2007). Specifically, the computational efficiency of intuitions allows them to regulate behavior quickly, and this sends an additional observable signal to social partners implying inflexible commitment (Critcher, Inbar, \& Pizarro, 2012; Krull, Seger, \& Silvera, 2008; Van de Calseyde, Keren, \& Zeelenberg, 2014). As described below, the benefits of intuitive prosocial behavior have been widely explored (Bear \& Rand, 2016; Frank, 1988; Hoffman, Yoeli, \& Nowak, 2015; Lotz, 2015; Rand, Greene, \& Nowak, 2012). The benefits of intuitive punishment (i.e., negative reciprocity) have received some attention as well (Jordan \& Rand, 2020). We propose that extortionate behavior should also benefit from intuition, and for the very same reasons.

\subsection{Intuitions solve the intertemporal challenge}

Intuitive processes have long been argued to establish and maintain commitment to behaviors that are immediately costly, but ultimately beneficial (Frank, 1988). Moral emotions like anger, guilt, pride, envy, and even love, are proposed to function as inflexible "commitment devices" (Frank, 1988, Haidt, 2003; Hirshleifer, 1987; Keltner \& Haidt, 2001; Schino \& Aureli, 2010; Trivers, 1971). Moral emotions motivate us to engage in materially costly prosocial behavior because they change the immediate payoff structure by adding intrinsic costs or benefits. For example, an honest individual will tip in a restaurant where she will never return because not tipping-even when justified by self-interest-will make her feel guilty.

Research on the psychological mechanisms underlying prosocial behavior supports a key role for intuition as a commitment device. Humans are famously persistent in behaving cooperatively even when it is not in our immediate best interests to do so (or notoriously so, as the economists would have it). For example, in one-shot anonymous interactions, the optimal decision is often defection. Yet many people opt to cooperate, even when they would have been better off defecting (e.g. Cooper, DeJong, Forsythe, \& Ross, 1996). In principle, automatic processes and emotions have the appropriate structure to generate behavior that contravenes rational self-interest.

expect inflexible extortion to emerge when it is relatively hard to learn that "the costs of extortion pay off eventually" while it is relatively easy to learn "resisting extortion is costly". Formalizing and verifying these extensions of past work remains for future work. 
Consistent with this possibility, considerable evidence suggests that intuitive decision-making often promotes "irrational" prosocial behavior. In anonymous one-shot games, individuals pressured to respond quickly are more cooperative than those who are given time to deliberate (Rand, Greene, \& Nowak, 2012; Rand et al., 2014; see Rand, 2016, for a metaanalysis). Likewise, when influenced to make their decisions in such games using instinct or emotion, participants tend to be more cooperative than when prompted to make their decisions using reasoning or logic (e.g., Rand, Greene, \& Nowak, 2012; Levine et al., 2018; Everett, Ingbretsen, Cushman, \& Cikara, 2017; see also Rand et al., 2014 for a review). Intuitive processes have also been used to explain reciprocal cooperation across species by minimizing the need for cognitively demanding computations to track costs and benefits (Brosnan \& de Waal, 2002; Freidin, Carballo, \& Bentosela, 2017; Schino \& Aureli, 2009; Schino \& Aureli, 2010; Schweinfurth \& Call, 2019).

Much of this evidence builds on a seminal paper arguing that intuition favors prosocial behavior in oneshot social dilemmas (Rand, Greene \& Nowak, 2012). This paper provided three forms of evidence: Prosocial decisions tend to be made faster, forcing fast decisions tends to increase prosociality, and "priming" participants to act intuitively tends to increase prosociality. Each line of evidence has been contested, and in different ways (e.g., Bouwmeester et al., 2017; Chen \& Krajbich 2018; Evans et al., 2015; Kvarven et al., 2020; Tinghög et al., 2013). Here we focus on the finding that manipulating decision-time affects cooperation. Meta-analytic evidence suggests this finding is quite robust when non-compliant participants are excluded (Rand, 2016), and this finding held in a large, multi-site, preregistered replication (Bouwmeester et al, 2017). On the other hand, in the standard paradigm, non-compliance occurred often and was highly asymmetric across conditions. Bouwmeester and colleagues showed that in this paradigm, when all participants were included in the analysis (an "intent to treat" approach), the effect of time pressure disappeared. More recently, methods have been developed to reduce noncompliance to trivial levels balanced across conditions both in the lab (Everett et al., 2017; Isler et al., 2018) and in the field (Artavia-Mora et al., 2017), with the consistent finding that shorter decision time are indeed associated with increased prosociality. Although further research is called for, these studies suggest that findings of increased prosociality under time pressure have some evidentiary weight.

Intuitive prosociality isn't constrained to intuitively cooperative behaviors, however. Both theoretical and empirical work supports a role for nondeliberative processes in negative reciprocity-i.e., punishment. One important line of theoretical work asks whether punishment is likely to be implemented as an instrumentally learned strategy (exhibiting flexibility) or instead as an evolved strategy, whether by biological or cultural evolution (exhibiting inflexibility) (Frank, 1988; Morris, et al., 2017). To learn a policy of negative reinforcement by trial and error is difficult whenever the relationship between one's own punishing behavior and a social partner's behavioral change will often be delayed and probabilistic. This will often be the case if a social partner's behavioral change must itself be learned. For instance, it might be hard for a parent to learn by trial and error that "time out" is an effective way of changing their toddler's behavior, precisely because it takes time for the toddler themselves to learn from time out. Thus, the effects of the parent's punishment will be delayed and probabilistic. Additionally, punishment typically bears an immediate cost (Raihani, Thornton, \& Bshary, 2012) - minimally its intrinsic energetic cost, but potentially also the cost of retaliation. A risk of relying on learning to acquire a punitive policy is that one will give up too soon, acquiescing to the social partner's undesirable behavior rather than persisting until punishment finally forces them to relent (Morris, McGlashan, Littman, \& Cushman, 2017). The alternative to learning a punishment policy, of course, is for it to be an adapted strategy at an evolutionary timescale, whether cultural or biological. Morris and colleagues (2017) showed that in such cases punishment may evolve to depend on "intuition". In principle the same logic might apply for other conditional control strategies (e.g., in cases of positive reciprocity), but this has not been formally explored.

Consistent with the predictions of these theoretical models, people appear committed to punishment even in circumstances where they know it holds no potential for long-run benefit (Boyd, Gintis, Bowles, \& Richerson, 2003; Fehr \& Fischbacher, 2003; Gardner \& West, 2004; Gintis, 2000; Henrich et al., 2006; Sigmund, Hauert, \& Nowak, 2001). Vignette studies find that punishment judgments mostly depend on simple retributive motives rather than a representation of its long-run advantages (Carlsmith, Darley, \& Robinson, 2002). This conclusion is reinforced by studies of punishment in economic games: People punish norm-violating behavior even in one-shot games, when it cannot improve their direct payoffs (Balafoutas, Grechenig, \& Nikiforakis, 2014; Fehr \& Fischbacher, 2004), even when it is anonymous, and thus cannot benefit their reputation (Güth, Schmittberger, Schwarze, 1982; Jordan, McAuliffe, \& Rand, 2015; Jordan \& Rand, 2020; Kahneman, Knetsch, Thaler, 1986; Straub \& Murnighan, 1995), in response to inequity even when 
no transgression has occurred (Deutchman, Bračič, Raihani, \& McAuliffe, 2020), and even when they have ample evidence that it will not change their social partner's behavior (Crockett, Özdemir, \& Fehr, 2014; Morris, MacGlashan, Littman \& Cushman, 2017). Punishment is often motivated by a specific emotion, anger (Nelissen \& Zeelenberg, 2009; Seip, Van Dijk, \& Rotteveel, 2014). Similarly, in studies of "cultures of honor", honor must be defended even in the face of far more powerful adversaries, pushing the potential costs of punishment beyond the point where it retains any expected value (Boehm, 1987; Miller, 2009; Nisbett, 2018). In addition, and consistent with the role of time pressure increasing prosocial behavior, several studies find that rejection rates are higher in an ultimatum game under time pressure (Grimm \& Mengel, 2011; Neo et al., 2013; Sutter et al., 2003). In sum, punishment appears to often depend on inflexible mechanisms that, whether inherited biologically or culturally, circumvent the intertemporal challenges of learning and motivation.

Given that intuitions, and particularly emotions, commit prosocial individuals to their cooperative strategy, we argue that they likely also drive strategic commitment for extortionate individuals. In other words, just as a person can be inflexibly committed to a fair distribution of resources, they can be committed to an unfair distribution. Extortionate individuals may feel entitled to an inequitable distribution of resources either because they perceive themselves as having contributed more to a collaborative effort or as innately more deserving ${ }^{5}$. Social ranking, power, or group membership may strongly influence this sense of deservingness (what Fiske, 1992, calls authority ranking), and this phenomenon is widely observable when members of groups with different levels of status, authority, or power interact. We hypothesize that just like prosocial individuals, extortionate individuals respond emotionally to their partners' willingness (or unwillingness) to help them achieve their desired distribution of resources. For the extorter, who believes she is entitled to an unfair distribution of resources, eliciting cooperation from her partner may evoke positive emotions like happiness or validation. On the other hand, engaging with a resistant partner may evoke anger or indignation. Whatever the specific emotional basis, they have the capacity to serve as commitment devices for the extorters, just as moral emotions do for prosocial individuals.

\subsection{Intuitions solve the communication challenge}

\footnotetext{
${ }^{5}$ Consistent with this idea, Biccheiri (2005) described fairness as a "local" concept, dependent on the "interpretation and the expectations and prescriptions that
}

Intuitions can help to overcome not only the intertemporal challenges inherent to conditional control strategies, but also the communication challenges. Because intuitions are inflexible, they can signal behavioral consistency to others. Intuitive action is detectable, either because it occurs quickly or is paired with a signal of the underlying motivating emotion. When others detect that we have acted intuitively, they make inferences about our character, disposition, or intentions (Ames \& Johar, 2009; Chritcher, Inbar, \& Pizarro, 2012; Everett, Pizarro, \& Crockett, 2016; Hilbe, Hoffman, \& Nowak, 2015; Hoffman, Yoeli, \& Nowak, 2015; Jordan, Hoffman, Nowak, \& Rand, 2016; Monin, Pizarro, \& Beer, 2007). For example, emotional displays that accompany a behavior increase the degree to which that behavior is seen as informative about the actor's true moral character (Krull, Seger, \& Silvera, 2008; Levine et al., 2018). The speed with which a person responds also acts as a cue to their underlying intentions. By observing others' thinking time, we make inferences about how difficult the decision waswhether they were certain in their decision or were considering many competing concerns (Critcher, Inbar, \& Pizarro, 2012; Van de Calseyde, Keren, \& Zeelenberg, 2014). Consequently, actors who make moral decisions more quickly are evaluated as having a better moral character because we see it as an easy decision (Chritcher, Inbar, \& Pizarro, 2012; Pizarro, Uhlmann, \& Salovey, 2003).

These character evaluations are then used both to predict a social partner's future behavior and to guide our decisions about how to interact with them (Levine, et al., 2018). For example, observers perceive uncalculating cooperation as a reliable signal of trustworthiness. Consequently, they entrust uncalculating cooperators with more money in a trust game (Jordan, Hoffman, \& Rand, 2016). This preference to cooperate with intuitive cooperators has been shown both when intuitive decision-making is signaled through quick responses and when decisionmakers forgo the opportunity to find out more information about the potential costs and benefits of their actions (Jordan, Hoffman, \& Rand, 2016; Hoffman, Yoeli, Nowak, 2015; Hilbe, Hoffman, \& Nowak, 2015).

While there is less direct research on the signaling power of intuitive punishment, punishing behavior, and in particular third-party punishment (paying a cost to punish a transgressor despite not being personally harmed by the transgression), has consistently been recognized for its capacity to signal future behavior.

surround them and vary with the objects, people, and situations to which they apply" (pg. 76). 


\section{EXTORTION, INTUITION, AND THE DARK SIDE OF RECIPROCITY}

For example, costly punishment is often interpreted as a signal of prosociality (Barclay, 2006; Horita, 2010; Jordan, Hoffman, Bloom, \& Rand, 2016; Krasnow, Cosmides, Pederson, \& Tooby, 2012; Nelissen, 2008; Raihani \& Bshary, 2015; Simpson, Harrell, \& Willer, 2013) and, when it is the only available response, does in fact accurately reflect future trustworthiness (Jordan et al., 2016). Costly third-party punishment also effectively signals a willingness to respond to future, direct harm with retaliation (Delton \& Krasnow, 2017; Krasnow, Delton, Cosmides, \& Tooby, 2016). Finally, it has been theorized that the "hair-trigger" punitive responses characteristic of cultures of honor play an important role in signaling inflexible commitment to social partners (Nisbett, 2018).

Meanwhile, expressions of anger (either through angry vocalizations or facial expressions) lend credibility to the threat of punishment (Reed, DeScioli, \& Pinker, 2014) and signal the firmness of one's intentions (Adams et al., 2006; Hinde, 1985; Keltner \& Haidt, 2001; Morris \& Keltner, 2000; Reed, DeScioli, \& Pinker, 2014; Yik, 1999). The better one is able to use emotional expressions to signal a commitment to punish, the faster others learn to avoid transgressing against the likely punisher. In fact, animals that effectively send an honest signal that they will behave aggressively when challenged are more likely to dominate competitors without even having to fight (Searcy and Nowicki, 2005; Zhang, 2018).

\subsection{Summary}

Intuitions provide a solution to the two central challenges faced by prosocial conditional control strategies, such as TFT and moralistic punishment. First, they establish and maintain commitment to prosocial action, overcoming its immediate costs. Second, intuitive prosocial behavior is reliably and accurately perceived by others as a signal of this commitment. In theory, intuition offers these benefits both in cases of negative and positive reciprocity. In practice, experimental work bears this out: Whether we are engaging in rewarding behavior to encourage future cooperation or punishing behavior to discourage future harmful action, intuitive and inflexible processes often play a key role.

\section{Current evidence for intuitive extortion and directions for future research}

While we know that extortion can and does emerge in some social interactions among the general population (Becks \& Milinski, 2019; Hilbe, Hagel, \& Milinski, 2016; Milinski, Hilbe, Semmann, Sommerfeld, \& Marotzke, 2016), there is little research on the cognitive mechanisms supporting this behavior. Therefore, the relationship between intuitive processes and extortionate behavior remains an open empirical question. There is, however, some circumstantial evidence that intuitive, automatic, and emotional processes may play a key role in extortion. We focus on two populations whose behavior or values closely resemble those of extorters: Individuals who exhibit signatures of psychopathy (often at subclinical levels), and individuals with competitive or pro-self social value orientations (SVO).

\subsection{Psychopathy and impulsive antisociality}

Psychopathic traits include many features we commonly associate with extortionate behavior. Among the diagnostic criteria for psychopathy are characteristics such as superficial charm, a failure to learn from experience, pathological egocentricity, lack of remorse or shame, grandiose sense of self-worth, pathological lying, and manipulative behavior (Cleckley, 1982; Hare, et al., 1990). Impulsivity is also a hallmark feature of psychopathy (Blackburn \& Coid, 1998; Dåderman, 1999; Hare, 1985; Jones \& Paulhus, 2011; Klinteberg, Humble, \& Schalling, 1992; Lynam, 1997; Malesza \& Ostaszewski, 2016; March, Grieve, Marrington \& Jonason, 2017; Stanford, Ebner, Patton \& Williams, 1994; Vitacco \& Rogers, 2001). Individuals high in psychopathy are also low in selfcontrol, have a tendency to discount future consequences, have high rates of attention deficit disorder (Abramowitz, Kosson, \& Seidenberg, 2004; Colledge \& Blair, 2001; Fowler et al., 2009; Piatigorsky \& Hinshaw, 2004; Sevecke, Kosson, \& Krischer, 2009), and reduced executive functioning more generally (reviewed in Morgan \& Lilienfeld, 2000).

Not only is psychopathy associated with domain general impulsivity but, more specifically, with "impulsive antisociality" (Benning, et al., 2005) or "self-centered impulsivity" (Lilienfield \& Widows, 2005) - in other words, a reckless and self-centered willingness to take advantage of others. The Psychopathology Personality Inventory (PPI; Lilienfield \& Andrews, 1996), the most commonly used tool to assess psychopathic traits in the general population, includes four subscales in its measure of self-centered impulsivity including Machiavellian Egocentricity (a tendency to look out for one's own interests' before others), Carefree Nonplanfulness (an absence of forethought), Impulsive Nonconformity (a reckless lack of concern for social rules), and Blame Externalization (a tendency to view others as the source of one's difficulties and to offer rationalizations for one's misbehavior) (Lilienfield \& Fowler, 2006). These four traits are highly correlated in individuals (Edens \& McDermott, 2010; Lilienfield \& Andrews, 
1996; Lilienfield \& Fowler, 2006; see Marcus, Fulton, \& Edens, 2013 for a meta-analysis) suggesting that the self-serving behavior in individuals high in psychopathy is supported not by careful planning but by impulsiveness and intuition.

Self-centered impulsiveness is associated with extortion-like anti-social behaviors. For example, selfcentered impulsiveness, more so than other aspects of psychopathy, is linked to increases in both impulsive aggression (aggression that occurs as a result of provocation and anger) and premeditated aggression (goal-directed aggression that is motivated by external rewards; Long et al., 2014). While evidence for the relationship between general psychopathy and cooperation in economic games has been mixed, selfcentered impulsiveness and its subscales have consistently been associated with decreased cooperation in both repeated (Mokros et al., 2008) and one-shot prisoner's dilemmas (Curry, Chesters, \& Viding, 2011). Interestingly, one study has found that incarcerated individuals who scored high on the Machiavellian Egocentricity and Impulsive Nonconformity subscales of the PPI not only cooperated less than individuals who showed less selfcentered impulsivity in a 40-round prisoner's dilemma, but they also achieved higher payoffs over the course of the game (Mokros, et al., 2008). Importantly, subjects were playing against a computerized dummy programmed to play a forgiving version of tit-for-tat called tit-for-two-tats, although they believed they were playing against a real partner. The high rates of defection and higher scores by individuals high in Machiavellian Egocentricity and Impulsive Nonconformity against the dummy strategy has two important implications. First, they were not defecting merely as a reaction to provocation by their partners, but rather to try to maximize their own, unfair advantage. Second, because tit-for-two-tats will punish defection if sufficiently provoked, achieving high scores against the tit-for-two-tats dummy requires a very specific pattern: defecting often enough to accrue a competitive advantage, despite occasional punishment; but cooperating enough to avoid persistent mutual defection. This mirrors the basic behavioral patterns predicted by models of extortionate zero-determinate strategies (Press \& Dyson, 2012; Stewart \& Plotkin, 2012).

The impulsive nature of psychopathic behavior has not typically been interpreted as an adaptive advantage. The study by Mokros and colleagues (2008), however, is certainly suggestive that it can be. Moreover, the close fit between the behavior described by Mokros et al., (2018) and those prescribed by models of extortionate $\mathrm{ZD}$ strategies raises the intriguing possibility that a psychopathic "strategy"
(Glenn, Kurzban, \& Raine, 2011) is best served through intuitive, impulsive antisocial behavior.

It is worth bearing in mind that the relationship between psychopathy and impulsivity is correlational rather than causal. However, in another group of individuals who tend to show extortion-like behavior (those with pro-self SVO) there is some evidence that their self-serving cooperative style is directly supported by intuitive decision-making. We turn to this research next.

\subsection{Self-interested Social Values Orientations}

Convergent evidence for the role of intuitive processes in self-serving, extortion-like behavior comes from research on social value orientations (SVO). SVO is a system for classifying individuals' cooperative styles based on how they divide resources between themselves and another player in a series of allocation decisions (Balliet, Parks, \& Joireman, 2009; Bartling, Fehr, Marechal, \& Schunk 2009; Fehr \& Schmidt, 1999; Rusbult \& Van Lange, 2003; Van Lange, 2000). Although the specific classifications vary across studies, individuals are generally thought to display one of several cooperative phenotypes including pro-social (maximizing the other player's payoff or maximizing equity), self-interested (maximizing personal payoff), and spiteful/envious or competitive (either minimizing the other player's payoff or prioritizing advantageous inequity). These cooperative styles have been shown to emerge early in childhood (Eisenberg, et al., 1999) and to be consistent both across contexts (Bogaert, Boone, Declerck, 2008; Poncela-Casasnovas et al., 2016; Van Lange, Agnew, Harinck, \& Steemers, 1997), and time (Eisenberg et al., 1999; Peysakhovich, Nowak, \& Rand, 2014), suggesting they serve as default approaches to cooperative engagement, rather than flexible, contextspecific strategies.

Most relevant to extortionate behavior are the SVO dimensions that prioritize personal gain without regard to the partner's payoff ("self-interested" SVO) or that attempt to maximize relative personal advantage over the partner ("competitive" SVO). Individuals in these groups, who are generally referred to as "pro-self" individuals, have been shown to defect at significantly higher rates in public goods games (De Cremer \& Van Vugt, 1999), resource dilemmas (Kramer, McClintock, \& Messick, 1986), and prisoner's dilemmas (Kuhlman \& Marshello, 1975). While individuals with a tendency to act prosocially are believed to do so intuitively (Cornellison, Dewitte, \& Warlop, 2011), pro-self individuals are thought to act selfishly by default, and require deliberative control to override their selfish impulses and act prosocially (Bogart et al., 2008). Likewise, pro-self 


\section{EXTORTION, INTUITION, AND THE DARK SIDE OF RECIPROCITY}

(but not prosocial) individuals become more competitive and inequity averse when under cognitive load (Haruno \& Frith, 2010; Haruno, Kimura, \& Frith, 2014) suggesting such behaviors are the default. Finally, recent research has found that intuitive responding results as or more often in selfish decisions as it does prosocial decisions (Bago, Bonnefon, \& DeNeys, 2021). The high rates of intuitive selfishness in this work suggests that intuitively selfish behavior may not be constrained to just individuals with proself SVO.

Individuals exhibiting a competitive SVO also show signs of behavioral inflexibility. For example, when playing repeated games of chicken - in which defecting on a cooperator leads to a high payoff but mutual defection is disastrous-participants with a competitive SVO chose to defect significantly more often than prosocial individuals (McClintock \& Liebrand, 1988). Crucially, they persisted in defecting even when playing with another player who was highly likely to defect, suggesting they were unwilling or were unable to flexibly optimize their strategy to the current context. Finally, research on deliberative versus intuitive cognitive styles finds that individuals with social preferences that seek to either maximize equity or minimize the other person's payoff are generally more intuitive thinkers than those who seek to maximize utility (Corgnet, Espin, HernanGonzalez, 2015). Taken together, this body of research is consistent with the idea that both prosocial and selfserving action can be intuitive depending on an individual's social preferences (Capraro, Jordan, \& Rand, 2014).

Finally, evidence from functional neuroimaging also supports a link between pro-self SVO and intuitive self-serving behavior. Compared to prosocial individuals, pro-self individuals exhibit greater activation in the ventral medial prefrontal cortex (a region associated with value-based decision-making) when making self-interested monetary decisions. On the other hand, pro-self individuals experience increased activation in the dorsal medial prefrontal cortex (a region associated with cognitive control) when choosing a non-costly other-benefiting allocation (Kuss et al., 2015). These findings suggest that for pro-self individuals, self-serving behavior is supported by default value representations, while other-serving behavior requires effortful control, and that the opposite is true for prosocial individuals. Neuroimaging research also suggests that prosocial and pro-self individuals have diverging emotional responses to advantageous inequity (receiving more than others) and disadvantageous inequity (receiving less than others). When evaluating monetary allocations between themselves and another individual, prosocial individuals' activation in the amygdala (closely linked to intuitive aversive responses and negative affect) increases linearly as advantageous inequity increases. On the other hand, pro-self individuals show the opposite response, with increasing amygdala activation as disadvantageous inequity increases (Haruno \& Frith, 2010; Haruno, Kimura, \& Frith, 2014). Although these results should be interpreted conservatively due to small sample sizes, they do suggest that for pro-self individuals, intuitive emotional responses may motivate behaviors that promote a personal advantage, whereas in prosocial individuals the same emotional responses may motivate behaviors that promote fairness and equity.

Both the behavioral and neuroimaging research on SVO suggest that individuals who seek a personal advantage do so in a way that relies on intuitive, emotion driven processes, rather than deliberative control. While the behavioral measures used to identify pro-self SVO involve unilateral choice, and thus preclude the assessment of conditional strategies, those with pro-self SVO are those who might be most highly motivated to engage in an extortionate conditional control strategy in order to achieve their preferred outcomes.

In sum, research on individuals who likely engage in extortion-like behaviors - those high in psychopathy or with pro-self SVO-suggests that much of their self-interested decision-making is dispositional and automatic. Moreover, research on intuitive action as a signal of future behavior suggests that intuitive selfishness effectively signals future antisocial action. Although circumstantial, this evidence suggests that extortionate strategies may be supported by intuitive processes, consistent with the proposal that intuition serves the same function for extortionate behavior as it does for prosocial behavior.

\subsection{Future directions}

To our knowledge there is no direct research on the cognitive mechanisms supporting extortionate behavior. Instead, current empirical work focuses primarily on the conditions under which extortionate behavior emerges (e.g. Becks \& Milinski, 2019; Bolle, Breitmoser, \& Schlachter, 2011; Hilbe, Hagel, \& Milinski, 2016; Milinski, et al., 2016; Milinski et al., 2008). Therefore, identifying the psychological factors that drive extortionate behavior is an important area for future research. As we have argued here, a promising starting point for understanding the psychological mechanism supporting extortion is to characterize its reliance on automatic vs. controlled processes. Support for our claims requires addressing two main questions: First, is there evidence that extortionate behavior is supported by intuitive 
decision-making? And second, does intuitive extortion solve the intertemporal and communication challenges faced by all conditional control strategies? Using the body of research on intuitive prosociality as a model, we identify likely sources of evidence to address these two questions.

Four lines of evidence have been used to argue that prosocial behavior relies on intuitive processes, and therefore could contribute to the claim that extortionate behavior does as well. First, research on individual differences in economic decision-making finds that pro-social decisions tend to occur more quickly than self-interested ones (e.g. Rand, Greene, \& Nowak, 2012). We might expect, then, that extorters tend to make their decisions more quickly than those who forgo opportunities to take advantage of a partner, particularly under conditions that foster extortionate behavior (for example when there is a power imbalance or when a competitive advantage is incentivized). Further, like reciprocal cooperators (e.g. Corgnet, Espín, \& Hernán-González, 2015), we predict that extorters will exhibit lower levels of cognitive reflection.

Second, past work on intuitive cooperation shows that experimental manipulations designed to reduce participants' ability to exert cognitive control, such as responding under time pressure or cognitive load, increase prosocial behavior (Cappelletti, Goth, \& Ploner, 2011; Conelissen, Dewitte, \& Warlop, 2011; Rand et al., 2012). Likewise, prompting participants to rely on their intuitions rather than deliberation to make their decisions also appears to increase prosocial decision-making (Rand, Greene, \& Nowak, 2012; Levine et al., 2018; Everett, Ingbretsen, Cushman, \& Cikara, 2017). If extortionate behavior is also motivated by intuitive processes, we predict that similar interventions (those that increase the use of intuitive responding and decrease the use of deliberation) would increase extortionate behavior. Once again, we expect this to be particularly true under contextual conditions that encourage extortion.

Third, neuroimaging research suggests that prosocial behavior preferentially engages brain regions associated with intuitive processes, such as reward seeking, rather than deliberative processes such as cognitive control (Tricomi, Rangel, Camerer, \& O'Doherty, 2010; Dawes et al., 2012; Hare, Cramer, Knoepfle, \& Rangel, 2010; Zaki \& Mitchell, 2011; Zaki, Lopez, \& Mitchell, 2014). Similarly, we would expect that extortionate decision-making would also be associated with activation in brain regions associated with emotion and reward, rather than with deliberation or control.

Finally, developmental research suggests that prosocial preferences and behavior emerge very early in ontogeny, consistent with the view that such preferences are intuitive (e.g. Hamilin, Wynn, \& Bloom, 2007; Shaw \& Olson, 2012; Warneken \& Tomasello, 2009). Importantly, it has not yet been asked how young children behave in contexts in which adults are most likely to engage in extortionate behavior (i.e. when there is a power imbalance or relative advantage is incentivized). We might expect that in these contexts, young children are more likely to behave extortionately than prosocially.

In addition to demonstrating that extortion relies on intuition, our argument rests on the claim that extortion is intuitive precisely because intuitions provide solutions to the particular challenges faced by extortion and other conditional control strategies; what we describe as the intertemporal and communicative challenges. Once again, we can look to the research on intuitive prosociality to identify the types of evidence we may find to support this claim.

In terms of the intertemporal challenge, we would expect that individuals who behave extortionately may persist in doing so even when it isn't in their selfinterest, such as in one-shot interactions, or when an extortionate strategy is likely to fail. Moreover, it may be that in repeated exchanges, many individuals try to seek a competitive advantage initially, but only those who do so intuitively are able to persist in such a strategy to achieve long-term gains.

Like intuitive cooperation, intuitive extortion should also signal strategic commitment to cooperative partners. Intuitive prosocial behavior is viewed as an indication of one's underlying prosocial disposition or character (e.g. Chritcher, Inbar, \& Pizarro, 2012). Similarly, we expect that intuitive extortion would be perceived as indicative of underlying personality characteristics or traits. Research has also demonstrated that those who make their decisions to behave prosocially in ways that appear intuitive (either by deciding quickly or by forgoing the opportunity to find out information about the costs of prosociality) are seen as more trustworthy in future interactions (e.g. Jordan, Hoffman, \& Rand, 2016). Intuitive extortion should have similar signaling power. Those who decide to extort quickly, or without evaluating the relevant costs, should be expected to behave similarly in the future. Importantly, partners of intuitive extorters should quickly learn that intuitive extorters will be unresponsive to attempts to change their behavior, increasing the likelihood that these unfortunate partners will surrender to being extorted.

\subsection{Alternatives}

There are several ways in which our proposal might be wrong. First, it is possible that extortionate behavior is not supported by intuition, but instead by 
deliberation. In other words, people may choose to act extortionately because they have an explicit representation of its benefits and have chosen their strategy deliberately in light of those benefits. Of course it is likely that extortion is at least sometimes a deliberative choice, and at least sometimes not, so the key question at stake is whether it is useful and accurate to describe intuitive extortion as a psychological regularity; that is, whether intuitive extortion is a widely-shared mechanism made available by the structure of the human mind. In order to resolve this question, it will be important not only to provide "existence proofs" of intuitive extortion (or deliberative extortion) in laboratory environments, but also to use a variety of methods to discern the form that extortion takes in real-world settings.

Second, it is possible that extortion is often supported by intuition, but not because it has the function of meeting the challenges of commitment and communication that we propose. For instance, extortionate instincts may have evolved at a period in our ancestry in which we did not have the intellectual capacity to implement extortion deliberately - in other words, when intuitive extortion was the only option. In this case, perhaps we retain the vestiges of this evolutionary ancient design, but not because of any particular functional advantage to intuitive extortion. One important source of evidence that can discriminate against these possibilities is to determine whether intuitive extortion in fact provides the benefits we propose: Does it help extorters remain committed, and does it help to communicate this commitment to the targets of extortion? Although identifying that these benefits are real cannot provide decisive evidence in favor of our adaptive hypothesis, it would provide some support. Meanwhile, if these benefits do not exist, it would provide strong evidence against our hypothesis.

\section{Conclusion}

A decade of research has established that prosocial behavior is often supported by intuitive, inflexible processes. We have argued that harmful and antisocial behavior is as well-and for the very same reasons. Intuition is a valuable tool for conditional control strategies - those that attempt to dictate their social partner's behaviors through some combination of carrot and stick. Conditional control strategies may function to achieve prosocial ends, enforcing norms and pursuing fair allocations of resources. Or, they may function to achieve antisocial ends, undermining norms and pursuing personal gain or advantage. In either case, to succeed, they must be implemented with sufficient inflexibility to persist despite short-term costs, and to convince social partners to accede.
An essential part of our analysis is to characterize strategies, rather than individual behaviors, as "prosocial" or "antisocial" (Bshary \& Bergmüller, 2007). Extortionate strategies can be implemented by behaviors that "help" (as in the case of a manager who gives promotions to those who work uncompensated hours), while prosocial strategies can be implemented by behaviors that harm (as in the case of the CEO who finds out and reprimands this manager). This manner of thinking at the level of strategies, rather than behavior, invites a broader realignment of our perspective on the relationship between intuition and social behavior. If our focus were on individual behaviors, we might have posed the question, "Does intuition support cooperation or defection?". Framed this way, the recent literature could be taken to suggest the answer is "cooperation"-and, therefore, that intuition promotes prosociality. Surely this is often true, but we suggest that intuitive cooperation can also serve antisocial ends. Meanwhile, as we have emphasized, a prosocial strategy such as TFT may benefit from intuitive (reciprocal) defection. Quickly, the question, "Does intuition support cooperation or defection?"- and any implied relationship to the question "Does intuition support prosocial or antisocial behavior?"- begins to look ill-posed.

We favor reorienting the inquiry around strategies, rather than the atomic behaviors of which they are composed. What makes tit-for-tat a prosocial strategy is not the behaviors it prescribes, but rather the division of resources that it functions to elicit: one in which value is created by, and equally shared between, both players. This same prosocial resource distribution can even be promoted by value-destroying behaviors, such as punishment. Meanwhile, certain zero determinant strategies use slightly altered mixtures of contingent cooperation and defection to elicit unfair, antisocial resource divisions: ones that disproportionately transfer value from one player to another.

As these examples illustrate, there is no simple mapping of individual behaviors to the categories "prosocial" or "antisocial", nor is there any simple mapping from intuition to simple behaviors such as "cooperation" or "defection". Rather, a more fruitful level of analysis is the strategy. We can reasonably categorize strategies as prosocial or antisocial, and we do so according to the resource divisions that they function to elicit. Finally, as we have argued, intuition is a useful tool for any conditional control strategy. In the appropriate context, we should be as likely to observe intuitive defection and punishment as we see intuitive cooperation and altruism. Across contexts, it is doubtful whether there will be any stable relationship between intuition and prosociality, or antisociality. What intuition promotes is, simply, 
effective social control - whether by carrot or by stick, and whether for good or ill.

\section{References}

Abramowitz, C. S., Kosson, D. S., \& Seidenberg, M. (2004). The relationship between childhood attention deficit hyperactivity disorder and conduct problems and adult psychopathy in male inmates. Personality and Individual Differences, 36(5), 1031-1047.

Adams, R. B., Ambady, N., Macrae, C. N., \& Kleck, R. E. (2006). Emotional expressions forecast approach-avoidance behavior. Motivation and Emotion, 30(2), 177-186.

Ågren, J. A., Davies, N. G., \& Foster, K. R. (2019). Enforcement is central to the evolution of cooperation. Nature Ecology \& Evolution, 3(7), 1018-1029.

Ames, D. R., \& Johar, G. V. (2009). I'll know what you're like when I see how you feel: How and when affective displays influence behaviorbased impressions. Psychological Science, 20(5), 586-593.

Andrighetto, G., \& Grieco, D. (2020). Peer effects on compliance with extortive requests. PloS One, 15(4), e0231879.Axelrod, R., \& Hamilton, W. D. (1981). The evolution of cooperation. Science, 211(4489), 1390-1396.

Artavia-Mora, L., Bedi, A. S., \& Rieger, M. (2017). Intuitive help and punishment in the field. European Economic Review, 92, 133-145.

Axtell, R. L., Epstein, J. M., \& Young, H. P. (2012). The emergence of classes in a multi-agent bargaining model. Princeton University Press.

Axelrod, R. (1980). Effective choice in the prisoner's dilemma. Journal of conflict resolution, 24(1), 3-25.

Axelrod, R., \& Hamilton, W. D. (1981). The evolution of cooperation. Science, 211(4489), 13901396.

Balliet, D., Parks, C., \& Joireman, J. (2009). Social value orientation and cooperation in social dilemmas: A meta-analysis. Group Processes \& Intergroup Relations, 12(4), 533-547.

Balafoutas, L., Grechenig, K., \& Nikiforakis, N. (2014). Third-party punishment and counterpunishment in one-shot interactions. Economics Letters, 122(2), 308-310.

Barclay, P. (2006). Reputational benefits for altruistic punishment. Evolution and Human Behavior, 27(5), 325-344.

Barnett, O. W. (2001). Why battered women do not leave, part 2: External inhibiting factors- social support and internal inhibiting factors. Trauma, Violence, \& Abuse, 2(1), 3-35.

Bartling, B., Fehr, E., Maréchal, M. A., \& Schunk, D. (2009). Egalitarianism and competitiveness. American Economic Review, 99(2), 93-98.

Baumard, N., \& Boyer, P. (2013). Explaining moral religions. Trends in Cognitive Sciences, 17(6), 272-280.

Bear, A., \& Rand, D. G. (2016). Intuition, deliberation, and the evolution of cooperation. Proceedings of the National Academy of Sciences, 113(4), 936-941.

Becks, L., \& Milinski, M. (2019). Extortion strategies resist disciplining when higher competitiveness is rewarded with extra gain. Nature Communications, 10(1), 1-9.

Benning, S. D., Patrick, C. J., Blonigen, D. M., Hicks, B. M., \& Iacono, W. G. (2005). Estimating facets of psychopathy from normal personality traits: A step toward community epidemiological investigations. Assessment, 12(1), 3-18.

Binmore, K., Morgan, P., Snaked, A., \& Sutton, J. (1991). Do people exploit their bargaining power? An experimental study. Games and Economic Behavior, 3(3), 295-322.

Binmore, K., Shared, A., \& Sutton, J. (1989). An outside option experiment. The Quarterly Journal of Economics, 104(4), 753-770.

Blackburn, R., \& Coid, J. W. (1998). Psychopathy and the dimensions of personality disorder in violent offenders. Personality and Individual Differences, 25(1), 129-145.

Boehm, C. (1987). Blood revenge: The enactment and management of conflict in Montenegro and other tribal societies. University of Pennsylvania Press.

Bogaert, S., Boone, C., \& Declerck, C. (2008). Social value orientation and cooperation in social dilemmas: A review and conceptual model. British Journal of Social Psychology, 47(3), 453-480.

Bolle, F., Breitmoser, Y., \& Schlächter, S. (2011). Extortion in the laboratory. Journal of Economic Behavior \& Organization, 78(3), 207-218.

Bowles, S., \& Naidu, S. (2006). Persistent institutions. Santa Fe Institute Working.

Bouwmeester, S., Verkoeijen, P. P., Aczel, B., Barbosa, F., Bègue, L., Brañas-Garza, P., ... \& Wollbrant, C. E. (2017). Registered replication report: Rand, greene, and nowak (2012). Perspectives on Psychological Science, 12(3), 527-542.

Boyd, R., Gintis, H., Bowles, S., \& Richerson, P. J. (2003). The evolution of altruistic 
punishment. Proceedings of the National Academy of Sciences, 100(6), 3531-3535.

Boyd, R., \& Richerson, P. J. (1992). Punishment allows the evolution of cooperation (or anything else) in sizable groups. Ethology and Sociobiology, 13(3), 171-195.

Brosnan, S. F., \& de Waal, F. B. M. (2002). A proximate perspective on reciprocal altruism. Human Nature, 13(1), 129-152.

Bruner, J. P. (2019). Minority (dis) advantage in population games. Synthese, 196(1), 413427.

Bruner, J., \& O'Connor, C. (2016). Power, bargaining, and collaboration.

Bshary, R., \& Bergmüller, R. (2008). Distinguishing four fundamental approaches to the evolution of helping. Journal of Evolutionary $b=$ Biology, 21(2), 405-420.

Bshary, R., \& Grutter, A. S. (2005). Punishment and partner switching cause cooperative behaviour in a cleaning mutualism. Biology Letters, 1(4), 396-399.

Bull, J. J., \& Rice, W. R. (1991). Distinguishing mechanisms for the evolution of cooperation. Journal of Theoretical Biology, 149(1), 63-74.

Camerer, C. F. (2011). Behavioral game theory: Experiments in strategic interaction. Princeton University Press.

Cant, M. A. (2011). The role of threats in animal cooperation. Proceedings of the Royal Society B: Biological Sciences, 278(1703), 170-178.

Carlsmith, K. M., Darley, J. M., \& Robinson, P. H. (2002). Why do we punish? Deterrence and just deserts as motives for punishment. Journal of Personality and Social Psychology, 83(2), 284.

Cappelletti, D., Güth, W., \& Ploner, M. (2011). Being of two minds: Ultimatum offers under cognitive constraints. Journal of Economic Psychology, 32(6), 940-950.

Capraro, V., Jordan, J. J., \& Rand, D. G. (2014). Heuristics guide the implementation of social preferences in one-shot Prisoner's Dilemma experiments. Scientific Reports, 4(1), 1-5.

Chen, F., \& Krajbich, I. (2018). Biased sequential sampling underlies the effects of time pressure and delay in social decision making. Nature Communications, 9(1), 1-10.

Chernyak, N., Leimgruber, K. L., Dunham, Y. C., Hu, J., \& Blake, P. R. (2019). Paying back people who harmed us but not people who helped us: Direct negative reciprocity precedes direct positive reciprocity in early development. Psychological Science, 30(9), 1273-1286.
Critcher, C. R., Inbar, Y., \& Pizarro, D. A. (2013). How quick decisions illuminate moral character. Social Psychological and Personality Science, 4(3), 308-315.

Cleckley, H. (1982). The mask of sanity. Mosby.

Clutton-Brock, T. H., \& Parker, G. A. (1995). Punishment in animal societies. Nature, 373(6511), 209-216.

Clutton-Brock, T. H., \& Parker, G. A. (1995). Sexual coercion in animal societies. Animal Behaviour, 49(5), 1345-1365.

Colledge, E., \& Blair, R. J. R. (2001). The relationship in children between the inattention and impulsivity components of attention deficit and hyperactivity disorder and psychopathic tendencies. Personality and Individual Differences, 30(7), 1175-1187.

Cornelissen, G., Dewitte, S., \& Warlop, L. (2011). Are social value orientations expressed automatically? decision making in the dictator game. Personality and Social Psychology Bulletin, 37(8), 1080-1090.

Cooper, R., DeJong, D. V., Forsythe, R., \& Ross, T. W. (1996). Cooperation without reputation: experimental evidence from prisoner's dilemma games. Games and Economic Behavior, 12(2), 187-218.

Corgnet, B., Espín, A. M., \& Hernán-González, R. (2015). The cognitive basis of social behavior: cognitive reflection overrides antisocial but not always prosocial motives. Frontiers in Behavioral Neuroscience, 9, 287.

Critcher, C. R., Inbar, Y., \& Pizarro, D. A. (2013). How quick decisions illuminate moral character. Social Psychological and Personality Science, 4(3), 308-315.

Crockett, M. J., Özdemir, Y., \& Fehr, E. (2014). The value of vengeance and the demand for deterrence. Journal of Experimental Psychology: General, 143(6), 2279.

Curry, O., Chesters, M. J., \& Viding, E. (2011). The psychopath's dilemma: The effects of psychopathic personality traits in one-shot games. Personality and Individual Differences, 50(6), 804-809.

Cushman, F., \& Morris, A. (2015). Habitual control of goal selection in humans. Proceedings of the National Academy of Sciences, 112(45), 13817-13822.

Dåderman, A. M. (1999). Differences between severely conduct-disordered juvenile males and normal juvenile males: The study of personality traits. Personality and Individual Differences, 26(5), 827-845. 


\section{EXTORTION, INTUITION, AND THE DARK SIDE OF RECIPROCITY}

Dawes, C. T., Loewen, P. J., Schreiber, D., Simmons, A. N., Flagan, T., McElreath, R., ... \& Paulus, M. P. (2012). Neural basis of egalitarian behavior. Proceedings of the National Academy of Sciences, 109(17), 6479-6483.

De Cremer, D., \& Van Vugt, M. (1999). Social identification effects in social dilemmas: A transformation of motives. European Journal of Social Psychology, 29(7), 871-893.

Delton, A. W., \& Krasnow, M. M. (2017). The psychology of deterrence explains why group membership matters for third-party punishment. Evolution and Human Behavior, 38(6), 734-743.

Deutchman, P., Bračič, M., Raihani, N., \& McAuliffe, K. (2021). Punishment is strongly motivated by revenge and weakly motivated by inequity aversion. Evolution and Human Behavior, 42(1), 12-20.he

Dreber, A., Rand, D. G., Fudenberg, D., \& Nowak, M. A. (2008). Winners don't punish. Nature, 452(7185), 348-351.

Dugatkin, L. A. (1997). Cooperation among animals: An evolutionary perspective. Oxford University Press, Oxford.

Edens, J. F., \& McDermott, B. E. (2010). Examining the construct validity of the Psychopathic Personality Inventory-Revised: Preferential correlates of fearless dominance and selfcentered impulsivity. Psychological Assessment, 22(1), 32.

Eisenberg, N., Guthrie, I. K., Murphy, B. C., Shepard, S. A., Cumberland, A., \& Carlo, G. (1999). Consistency and development of prosocial dispositions: A longitudinal study. Child Development, 70(6), 1360-1372.

Erev, I., \& Roth, A. E. (1998). Predicting how people play games: Reinforcement learning in experimental games with unique, mixed strategy equilibria. American Economic Review, 88, 848-881.

Evans, J. S. B. (2003). In two minds: Dual-process accounts of reasoning. Trends in Cognitive Sciences, 7(10), 454-459.

Everett, J. A., Ingbretsen, Z., Cushman, F., \& Cikara, M. (2017). Deliberation erodes cooperative behavior-Even towards competitive outgroups, even when using a control condition, and even when eliminating selection bias. Journal of Experimental Social Psychology, 73, 76-81.

Everett, J. A., Pizarro, D. A., \& Crockett, M. J. (2016). Inference of trustworthiness from intuitive moral judgments. Journal of Experimental Psychology: General, 145(6), 772.
Fehr, E., \& Fischbacher, U. (2003). The nature of human altruism. Nature, 425(6960), 785791.

Fehr, E., \& Fischbacher, U. (2004). Social norms and human cooperation. Trends in Cognitive Sciences, 8(4), 185-190.

Fehr, E., Fischbacher, U., \& Gächter, S. (2002). Strong reciprocity, human cooperation, and the enforcement of social norms. Human Nature, 13(1), 1-25.

Fehr, E., \& Gächter, S. (2000). Fairness and retaliation: The economics of reciprocity. Journal of Economic Perspectives, 14(3), 159-181.

Fehr, E., \& Gächter, S. (2003). The puzzle of human cooperation. Nature, 421(6926), 912-912.

Fehr, E., \& Schmidt, K. M. (1999). A theory of fairness, competition, and cooperation. The Quarterly Journal of Economics, 114(3), 817-868.

FeldmanHall, O., Sokol-Hessner, P., Van Bavel, J. J., \& Phelps, E. A. (2014). Fairness violations elicit greater punishment on behalf of another than for oneself. Nature Communications, 5(1), 1-6.

Fiske, A. P. (1992). The four elementary forms of sociality: framework for a unified theory of social relations. Psychological Review, 99(4), 689.

Fowler, T., Langley, K., Rice, F., Whittinger, N., Ross, K., van Goozen, S., ... \& Thapar, A. (2009). Psychopathy traits in adolescents with childhood attention-deficit hyperactivity disorder. The British Journal of Psychiatry, 194(1), 62-67.

Frank, R. H. (1988). Passions within reason: The strategic role of the emotions. WW Norton \& Co.

Freidin, E., Carballo, F., \& Bentosela, M. (2017). Direct reciprocity in animals: the roles of bonding and affective processes. International Journal of Psychology, 52(2), 163-170.

Fudenberg, D., Drew, F., Levine, D. K., \& Levine, D. K. (1998). The theory of learning in games (Vol. 2). MIT press.

Gardner, A., \& West, S. A. (2004). Cooperation and punishment, especially in humans. The American Naturalist, 164(6), 753-764.

Gintis, H. (2000). Strong reciprocity and human sociality. Journal of Theoretical Biology, 206(2), 169-179.

Gintis, H., Henrich, J., Bowles, S., Boyd, R., \& Fehr, E. (2008). Strong reciprocity and the roots of human morality. Social Justice Research, 21(2), 241-253. 
Glenn, A. L., Kurzban, R., \& Raine, A. (2011). Evolutionary theory and psychopathy. Aggression and Violent Behavior, 16(5), 371380.

Green, L., Fry, A. F., \& Myerson, J. (1994). Discounting of delayed rewards: A life-span comparison. Psychological Science, 5(1), 3336.

Grimm, V., \& Mengel, F. (2009). Cooperation in viscous populations-experimental evidence. Games and Economic Behavior, 66(1), 202-220.

Gross, M. R., \& Repka, J. (1998). Stability with inheritance in the conditional strategy. Journal of Theoretical Biology, 192(4), 445453.

Güth, W., Schmittberger, R., \& Schwarze, B. (1982). An experimental analysis of ultimatum bargaining. Journal of Economic Behavior \& Organization, 3(4), 367-388.

Haidt, J. (2003). The moral emotions. In R. J. Davidson, K. R. Scherer, \& H. H. Goldsmith (Eds.), Series in affective science. Handbook of affective sciences (pp. 852-870). Oxford University Press.

Hamlin, J. K., Wynn, K., \& Bloom, P. (2007). Social evaluation by preverbal infants. Nature, 450(7169), 557-559.

Hare, R. D. (1985). Comparison of procedures for the assessment of psychopathy. Journal of Consulting and Clinical psychology, 53(1), 7.

Hare, T. A., Camerer, C. F., Knoepfle, D. T., O'Doherty, J. P., \& Rangel, A. (2010). Value computations in ventral medial prefrontal cortex during charitable decision making incorporate input from regions involved in social cognition. Journal of Neuroscience, 30(2), 583-590.

Hare, R.D., Harpur, T.J., Hakstian, A.R., Forth, A.E., Hart, S.D., \& Newman, J.P., (1990). The Revised Psychopathy Checklist: Descriptive statistics, reliability, and factor structure. Psychological Assessment: A Journal of Consulting and Clinical Psychology, 2, 338341.

Harsanyi, J. C., \& Selten, R. (1988). A general theory of equilibrium selection in games. MIT Press Books, 1 .

Haruno, M., \& Frith, C. D. (2010). Activity in the amygdala elicited by unfair divisions predicts social value orientation. Nature Neuroscience, 13(2), 160-161.

Haruno, M., Kimura, M., \& Frith, C. D. (2014). Activity in the nucleus accumbens and amygdala underlies individual differences in prosocial and individualistic economic choices. Journal of Cognitive Neuroscience, 26(8), 1861-1870.

He, Z., Geng, Y., Shen, C., \& Shi, L. (2020). Evolution of cooperation in the spatial Prisoner's Dilemma game with extortion strategy under win-stay-lose-move rule. Chaos, Solitons \& Fractals, 141, 110421.

Henrich, J., Ensminger, J., McElreath, R., Barr, A., Barrett, C., Bolyanatz, A., ... \& Ziker, J. (2010). Markets, religion, community size, and the evolution of fairness and punishment. Science, 327(5972), 1480-1484.

Henrich, J., McElreath, R., Barr, A., Ensminger, J., Barrett, C., Bolyanatz, A., ... \& Ziker, J. (2006). Costly punishment across human societies. Science, 312(5781), 1767-1770.

Hilbe, C., Chatterjee, K., \& Nowak, M. A. (2018). Partners and rivals in direct reciprocity. Nature Human Behaviour, 2(7), 469-477.

Hilbe, C., Hagel, K., \& Milinski, M. (2016). Asymmetric power boosts extortion in an economic experiment. PLoS One, 11(10), e0163867.

Hilbe, C., Hoffman, M., \& Nowak, M. A. (2015). Cooperate without looking in a non-repeated game. Games, 6(4), 458-472.

Hilbe, C., Nowak, M. A., \& Sigmund, K. (2013). Evolution of extortion in iterated prisoner's dilemma games. Proceedings of the National Academy of Sciences, 110(17), 6913-6918.

Hinde, R. A. (1985). Was 'The expression of the emotions' a misleading phrase?. Animal Behaviour, 33(3), 985-992.

Hirshleifer, J. (1987). On the emotions as guarantors of threats and promises. The latest on the best: Essays on evolution and optimality, 307-26.

Hoffmann, R. (2006). The cognitive origins of social stratification. Computational Economics, 28(3), 233-249.

Hoffman, M., Yoeli, E., \& Nowak, M. A. (2015). Cooperate without looking: Why we care what people think and not just what they do. Proceedings of the National Academy of Sciences, 112(6), 1727-1732.

Horita, Y. (2010). Punishers may be chosen as providers but not as recipients. Letters on Evolutionary Behavioral Science, 1(1), 6-9.

Isler, O., Maule, J., \& Starmer, C. (2018). Is intuition really cooperative? Improved tests support the social heuristics hypothesis. PloS One, 13(1), e0190560.

Jensen, K. (2010). Punishment and spite, the dark side of cooperation. Philosophical Transactions of the Royal Society B: Biological Sciences, 365(1553), 2635-2650. 
Jones, D. N., \& Paulhus, D. L. (2011). The role of impulsivity in the Dark Triad of personality. Personality and Individual Differences, 51(5), 679-682.

Jordan, J. J., Hoffman, M., Bloom, P., \& Rand, D. G. (2016). Third-party punishment as a costly signal of trustworthiness. Nature, 530(7591), 473-476.

Jordan, J. J., Hoffman, M., Nowak, M. A., \& Rand, D. G. (2016). Uncalculating cooperation is used to signal trustworthiness. Proceedings of the National Academy of Sciences, 113(31), 8658-8663.

Jordan, J., McAuliffe, K., \& Rand, D. (2016). The effects of endowment size and strategy method on third party punishment. Experimental Economics, 19(4), 741-763.

Jordan, J. J., \& Rand, D. G. (2020). Signaling when no one is watching: A reputation heuristics account of outrage and punishment in oneshot anonymous interactions. Journal of Personality and Social Psychology, 118(1), 57.

Kahneman, D. (2011). Thinking, fast and slow. Macmillan.

Kahneman, D., Knetsch, J. L., \& Thaler, R. H. (1986). Fairness and the assumptions of economics. Journal of Business, S285-S300.

Keltner, D., \& Haidt, J. (2001). Social functions of emotions. In T. J. Mayne \& G. A. Bonanno (Eds.), Emotions and social behavior. Emotions: Current issues and future directions (p. 192-213). Guilford Press.

Klinteberg, B., Humble, K., \& Schalling, D. (1992). Personality and psychopathy: a longitudinal study of male subjects. European Journal of Personality, 6, 39-43.

Kramer, R. M., McClintock, C. G., \& Messick, D. M. (1986). Social values and cooperative response to a simulated resource conservation crisis. Journal of Personality, 54(3), 576-582.

Krasnow, M. M., Cosmides, L., Pedersen, E. J., \& Tooby, J. (2012). What are punishment and reputation for?. PLOS One, 7(9), e45662.

Krasnow, M. M., Delton, A. W., Cosmides, L., \& Tooby, J. (2016). Looking under the hood of third-party punishment reveals design for personal benefit. Psychological Science, 27(3), 405-418.

Krull, D. S., Seger, C. R., \& Silvera, D. H. (2008). Smile when you say that: Effects of willingness on dispositional inferences. Journal of Experimental Social Psychology, 44(3), 735-742.
Kuhlman, D. M., \& Marshello, A. F. (1975). Individual differences in game motivation as moderators of preprogrammed strategy effects in prisoner's dilemma. Journal of Personality and Social Psychology, 32(5), 922.

Kuss, K., Falk, A., Trautner, P., Montag, C., Weber, B., \& Fliessbach, K. (2015). Neuronal correlates of social decision making are influenced by social value orientation - an fMRI study. Frontiers in Behavioral Neuroscience, 9, 40.

Kvarven, A., Strømland, E., Wollbrant, C., Andersson, D., Johannesson, M., Tinghög, G., ... \& Myrseth, K. O. R. (2020). The intuitive cooperation hypothesis revisited: a metaanalytic examination of effect size and between-study heterogeneity. Journal of the Economic Science Association, 6(1), 26-42.

Levine, E. E., Barasch, A., Rand, D., Berman, J. Z., \& Small, D. A. (2018). Signaling emotion and reason in cooperation. Journal of Experimental Psychology: General, 147(5), 702.

Lilienfeld, S. O., \& Andrews, B. P. (1996). Development and preliminary validation of a self-report measure of psychopathic personality traits in noncriminal population. Journal of Personality Assessment, 66(3), 488-524.

Lilienfeld, S. O., \& Fowler, K. A. (2006). The SelfReport Assessment of Psychopathy: Problems, Pitfalls, and Promises. In C. J. Patrick (Ed.), Handbook of psychopathy (p. 107-132). The Guilford Press.

Lilienfeld, S. O., Widows, M. R., \& Staff, P. A. R. (2005). Psychopathic personality inventoryrevised. Social Influence (SOI), 61(65), 97.

Long, K., Felton, J. W., Lilienfeld, S. O., \& Lejuez, C. W. (2014). The role of emotion regulation in the relations between psychopathy factors and impulsive and premeditated aggression. Personality Disorders: Theory, Research, and Treatment, 5(4), 390.

Lotz, S. (2015). Spontaneous giving under structural inequality: Intuition promotes cooperation in asymmetric social dilemmas. PloS One, 10(7), e0131562.

Lynam, D. R. (1997). Pursuing the psychopath: Capturing the fledgling psychopath in a nomological net. Journal of Abnormal Psychology, 106(3), 425.

Macy, M. W., \& Flache, A. (2002). Learning dynamics in social dilemmas. Proceedings of the National Academy of Sciences, 99(suppl 3), 7229-7236. 


\section{EXTORTION, INTUITION, AND THE DARK SIDE OF RECIPROCITY}

Malesza, M., \& Ostaszewski, P. (2016). Dark side of impulsivity - Associations between the Dark Triad, self-report and behavioral measures of impulsivity. Personality and Individual Differences, 88, 197-201.

March, E., Grieve, R., Marrington, J., \& Jonason, P. K. (2017). Trolling on Tinder $\AA$ (and other dating apps): Examining the role of the Dark Tetrad and impulsivity. Personality and Individual Differences, 110, 139-143.

Marcus, D. K., Fulton, J. J., \& Edens, J. F. (2013). The two-factor model of psychopathic personality: Evidence from the Psychopathic Personality Inventory. Personality Disorders: Theory, Research, and Treatment, 4(1), 67.

Marr, D., \& Poggio, T. (1976). From understanding computation to understanding neural circuitry. A.I. Memo(357), 1-22.

Martin, J. W., \& Cushman, F. (2015). To punish or to leave: Distinct cognitive processes underlie partner control and partner choice behaviors. PloS One, 10(4), e0125193.

Mathew, S., \& Boyd, R. (2011). Punishment sustains large-scale cooperation in prestate warfare. Proceedings of the National Academy of Sciences, 108(28), 11375-11380.

McClintock, C. G., \& Liebrand, W. B. (1988). Role of interdependence structure, individual value orientation, and another's strategy in social decision making: A transformational analysis. Journal of Personality and Social Psychology, 55(3), 396.

McElreath, R., Boyd, R., \& Richerson, P. (2003). Shared norms and the evolution of ethnic markers. Current anthropology, 44(1), 122130.

Melis, A. P., \& Semmann, D. (2010). How is human cooperation different?. Philosophical Transactions of the Royal Society B: Biological Sciences, 365(1553), 2663-2674.

Milinski, M., Hilbe, C., Semmann, D., Sommerfeld, R., \& Marotzke, J. (2016). Humans choose representatives who enforce cooperation in social dilemmas through extortion. Nature Communications, 7(1), 1-9.

Milinski, M., Sommerfeld, R. D., Krambeck, H. J., Reed, F. A., \& Marotzke, J. (2008). The collective-risk social dilemma and the prevention of simulated dangerous climate change. Proceedings of the National Academy of Sciences, 105(7), 2291-2294.

Miller, W. I. (2009). Bloodtaking and peacemaking: Feud, law, and society in Saga Iceland. University of Chicago press.
Mokros, A., Menner, B., Eisenbarth, H., Alpers, G. W., Lange, K. W., \& Osterheider, M. (2008). Diminished cooperativeness of psychopaths in a prisoner's dilemma game yields higher rewards. Journal of Abnormal Psychology, 117(2), 406.

Monin, B., Pizarro, D. A., \& Beer, J. S. (2007). Deciding versus reacting: Conceptions of moral judgment and the reason-affect debate. Review of general psychology, 11(2), 99-111.

Mookherjee, D., \& Sopher, B. (1994). Learning behavior in an experimental matching pennies game. Games and Economic Behavior, 7(1), 62-91.

Morgan, A. B., \& Lilienfeld, S. O. (2000). A metaanalytic review of the relation between antisocial behavior and neuropsychological measures of executive function. Clinical Psychology Review, 20(1), 113-136.

Morris, M. W., \& Keltner, D. (2000). How emotions work: The social functions of emotional expression in negotiations. Research in Organizational Behavior, 22, 1-50.

Morris, A., MacGlashan, J., Littman, M. L., \& Cushman, F. (2017). Evolution of flexibility and rigidity in retaliatory punishment. Proceedings of the National Academy of Sciences, 114(39), 10396-10401.

Nakao, H., \& Machery, E. (2012). The evolution of punishment. Biology \& Philosophy, 27(6), 833-850.

Nash, J. (1950). The Bargaining Problem. Econometrica, 18(2), 155-162.

Nash, J. (1953). Two-person cooperative games. Econometrica: Journal of the Econometric Society, 21(1) 128-140.

Nelissen, R. M. (2008). The price you pay: Costdependent reputation effects of altruistic punishment. Evolution and Human Behavior, 29(4), 242-248.

Nelissen, R. M., \& Zeelenberg, M. (2009). Moral emotions as determinants of third-party punishment: Anger, guilt and the functions of altruistic sanctions. Judgment and Decision Making, 4(7), 543.

Neo, W. S., Yu, M., Weber, R. A., \& Gonzalez, C. (2013). The effects of time delay in reciprocity games. Journal of Economic Psychology, 34, 20-35.

Nikiforakis, N., Oechssler, J., \& Shah, A. (2014). Hierarchy, coercion, and exploitation: An experimental analysis. Journal of Economic Behavior \& Organization, 97, 155-168.

Nisbett, R. E. (2018). Culture of honor: The psychology of violence in the South. Routledge. 


\section{EXTORTION, INTUITION, AND THE DARK SIDE OF RECIPROCITY}

Noë, R., Van Schaik, C. P., \& Van Hooff, J. A. R. A. M. (1991). The market effect: an explanation for pay-off asymmetries among collaborating animals. Ethology. Berlin, Hamburg, 87(1), 97-118.

Nowak, M. A. (2006). Five rules for the evolution of cooperation. Science, 314(5805), 1560-1563.

Nowak, M., \& Sigmund, K. (1990). The evolution of stochastic strategies in the prisoner's dilemma. Acta Applicandae Mathematicae, 20(3), 247-265.

Nowak, M. A., Tarnita, C. E., \& Antal, T. (2010). Evolutionary dynamics in structured populations. Philosophical Transactions of the Royal Society B: Biological Sciences, 365(1537), 19-30.

O'Connor, C. (2019). The origins of unfairness: Social categories and cultural evolution. Oxford University Press, USA.

Peysakhovich, A., Nowak, M. A., \& Rand, D. G. (2014). Humans display a 'cooperative phenotype' that is domain general and temporally stable. Nature Communications, $5(1), 1-8$

Phillips, T. (2018). The concepts of asymmetric and symmetric power can help resolve the puzzle of altruistic and cooperative behaviour. Biological Reviews, 93(1), 457-468.

Pizarro, D., Uhlmann, E., \& Salovey, P. (2003). Asymmetry in judgments of moral blame and praise: The role of perceived metadesires. Psychological Science, 14(3), 267-272.

Piatigorsky, A., \& Hinshaw, S. P. (2004). Psychopathic traits in boys with and without attention-deficit/hyperactivity disorder: Concurrent and longitudinal correlates. Journal of Abnormal Child Psychology, 32(5), 535-550.

Pollack, A., (2015, September 20). Drug goes from $\$ 13.50$ a tablet to $\$ 750$, overnight. The New York

Times. https:/www.nytimes.com/2015/09/21/busin ess/a-huge-overnight-increase-in-a-drugsprice-raises-protests.html

Poncela-Casasnovas, J., Gutiérrez-Roig, M., GraciaLázaro, C., Vicens, J., Gómez-Gardeñes, J., Perelló, J., ... \& Sánchez, A. (2016). Humans display a reduced set of consistent behavioral phenotypes in dyadic games. Science Advances, 2(8), e1600451.

Poza, D. J., Villafáñez, F. A., Pajares, J., LópezParedes, A., \& Hernández, C. (2011). New insights on the Emergence of Classes Model. Discrete Dynamics in Nature and Society, 2011.
Press, W. H., \& Dyson, F. J. (2012). Iterated Prisoner's Dilemma contains strategies that dominate any evolutionary opponent. Proceedings of the National Academy of Sciences, 109(26), 10409-10413.

Raihani, N. J., \& Bshary, R. (2011). Resolving the iterated prisoner's dilemma: theory and reality. Journal of Evolutionary Biology, 24(8), 1628-1639.

Raihani, N. J., \& Bshary, R. (2015). The reputation of punishers. Trends in Ecology \& Evolution, 30(2), 98-103.

Raihani, N. J., \& Bshary, R. (2019). Punishment: one tool, many uses. Evolutionary Human Sciences, 1(e12), 1-26.

Raihani, N. J., Thornton, A., \& Bshary, R. (2012). Punishment and cooperation in nature. Trends in Ecology \& Evolution, 27(5), 288295.

Rand, D. G. (2016). Cooperation, fast and slow: Metaanalytic evidence for a theory of social heuristics and self-interested deliberation. Psychological Science, 27(9), 1192-1206.

Rand, D. G., Greene, J. D., \& Nowak, M. A. (2012). Spontaneous giving and calculated greed. Nature, 489(7416), 427-430.

Rand, D. G., Peysakhovich, A., Kraft-Todd, G. T., Newman, G. E., Wurzbacher, O., Nowak, M. A., \& Greene, J. D. (2014). Social heuristics shape intuitive cooperation. Nature Communications, 5(1), 1-12.

Reed, L. I., DeScioli, P., \& Pinker, S. A. (2014). The commitment function of angry facial expressions. Psychological Science, 25(8), 1511-1517.

Ridgeway, C. L. (2011). Framed by gender: How gender inequality persists in the modern world. Oxford University Press.

Roberts, G. (1998). Competitive altruism: from reciprocity to the handicap principle. Proceedings of the Royal Society of London. Series B: Biological Sciences, 265(1394), 427-431.

Rusbult, C. E., \& Van Lange, P. A. (2003). Interdependence, interaction, and relationships. Annual Review of Psychology, 54(1), 351-375.

Schelling, T. C. (1980). The Strategy of Conflict. Harvard university Press.

Schino, G., \& Aureli, F. (2009). Reciprocal altruism in primates: partner choice, cognition, and emotions. Advances in the Study of Behavior, 39, 45-69.

Schino, G., \& Aureli, F. (2010b). Primate reciprocity and its cognitive requirements. Evolutionary Anthropology, 19(4), 130-135 
Schino, G., \& Aureli, F. (2017). Reciprocity in groupliving animals: Partner control versus partner choice. Biological Reviews, 92(2), 665-672.

Schweinfurth, M. K., \& Call, J. (2019). Reciprocity: Different behavioural strategies, cognitive mechanisms and psychological processes. Learning \& Behavior, 47(4), 284-301.

Searcy, W. A., \& Nowicki, S. (2005). The evolution of animal communication: reliability and deception in signaling systems. Princeton University Press.

Seip, E. C., van Dijk, W. W., \& Rotteveel, M. (2009). On hotheads and Dirty Harries: the primacy of anger in altruistic punishment. Annals of the New York Academy of Sciences, 1167(1), 190-196.

Sevecke, K., Kosson, D. S., \& Krischer, M. K. (2009). The relationship between attention deficit hyperactivity disorder, conduct disorder, and psychopathy in adolescent male and female detainees. Behavioral Sciences \& the Law, 27(4), 577-598.

Shaw, A., \& Olson, K. R. (2012). Children discard a resource to avoid inequity. Journal of Experimental Psychology: General, 141(2), 382.

Sigmund, K., \& Nowak, M. A. (1999). Evolutionary game theory. Current Biology, 9(14), R503R505

Sigmund, K., Hauert, C., \& Nowak, M. A. (2001). Reward and punishment. Proceedings of the National Academy of Sciences, 98(19), 10757-10762.

Simpson, B., Harrell, A., \& Willer, R. (2013). Hidden paths from morality to cooperation: Moral judgments promote trust and trustworthiness. Social Forces, 91(4), 1529-1548.

Smith, J. M. (1979). Game theory and the evolution of behaviour. Proceedings of the Royal Society of London. Series B. Biological Sciences, 205(1161), 475-488.

Smith, E. A., \& Choi, J. K. (2007). The emergence of inequality in small-scale societies: Simple scenarios and agent-based simulations. In Timothy A. Kohler \& Sander E. van der Leeuw (eds), The model-based archaeology of socionatiural systems, 105-120. Santa Fe, NM: SAR Press.

Stanford, M. S., Ebner, D., Patton, J. H., \& Williams, J. (1994). Multi-impulsivity within an adolescent psychiatric population. Personality and Individual Differences, 16(3), 395-402.

Stewart, Q. T. (2010). Big bad racists, subtle prejudice and minority victims: An agent-based analysis of the dynamics of racial inequality.
In annual meeting of the Population Association of America.

Stewart, A. J., \& Plotkin, J. B. (2012). Extortion and cooperation in the Prisoner's Dilemma. Proceedings of the National Academy of Sciences, 109(26), 10134-10135.

Stewart, A. J., \& Plotkin, J. B. (2013). From extortion to generosity, evolution in the iterated prisoner's dilemma. Proceedings of the National Academy of Sciences, 110(38), 15348-15353.

Straub, P. G., \& Murnighan, J. K. (1995). An experimental investigation of ultimatum games: Information, fairness, expectations, and lowest acceptable offers. Journal of Economic Behavior \& Organization, 27(3), 345-364.

Sutter, M., Kocher, M., \& Strauß, S. (2003). Bargaining under time pressure in an experimental ultimatum game. Economics Letters, 81(3), 341-347.

Thaler, R. H. (1988). Anomalies: The ultimatum game. Journal of Economic Perspectives, 2(4), 195-206.

Tinghög, G., Andersson, D., Bonn, C., Böttiger, H., Josephson, C., Lundgren, G., ... \& Johannesson, M. (2013). Intuition and cooperation reconsidered. Nature, 498(7452), E1-E2.

Tricomi, E., Rangel, A., Camerer, C. F., \& O'Doherty, J. P. (2010). Neural evidence for inequalityaverse social preferences. Nature, 463(7284), 1089-1091.

Trivers, R. L. (1971). The evolution of reciprocal altruism. The Quarterly Review of Biology, 46(1), 35-57.

Warneken, F., \& Tomasello, M. (2009). Varieties of altruism in children and chimpanzees. Trends in Cognitive Sciences, 13(9), 397-402.

Wang, Z., Zhou, Y., Lien, J. W., Zheng, J., \& Xu, B. (2016). Extortion can outperform generosity in the iterated prisoner's dilemma. Nature Communications, 7(1), 1-7.

Walker, M., \& Wooders, J. (2001). Minimax play at Wimbledon. American Economic Review, 91(5), 1521-1538.

West, S. A., Griffin, A. S., \& Gardner, A. (2007). Social semantics: altruism, cooperation, mutualism, strong reciprocity and group selection. Journal of evolutionary biology, 20(2), 415-432.

Van de Calseyde, P. P., Keren, G., \& Zeelenberg, M. (2014). Decision time as information in judgment and choice. Organizational Behavior and Human Decision Processes, 125(2), 113-122. 
EXTORTION, INTUITION, AND THE DARK SIDE OF RECIPROCITY

Van Lange, P. A. (2000). Beyond self-interest: A set of propositions relevant to interpersonal orientations. European Review of Social Psychology, 11(1), 297-331.

Van Lange, P. A., Agnew, C. R., Harinck, F., \& Steemers, G. E. (1997). From game theory to real life: How social value orientation affects willingness to sacrifice in ongoing close relationships. Journal of Personality and Social Psychology, 73(6), 1330.

Vitacco, M. J., \& Rogers, R. (2001). Predictors of adolescent psychopathy: The role of impulsivity, hyperactivity, and sensation seeking. Journal of the American Academy of Psychiatry and the Law, 29(4), 374-382.
Yik, M. S. (1999). Interpretation of faces: A crosscultural study of a prediction from Fridlund's theory. Cognition \& Emotion, 13(1), 93-104.

Zaki, J., López, G., \& Mitchell, J. P. (2014). Activity in ventromedial prefrontal cortex co-varies with revealed social preferences: evidence for person-invariant value. Social Cognitive and Affective Neuroscience, 9(4), 464-469.

Zaki, J., \& Mitchell, J. P. (2013). Intuitive prosociality. Current Directions in Psychological Science, 22(6), 466-470.

Zhang, J. (2018). The human anger face likely carries a dual-signaling function. Frontiers in Behavioral Neuroscience, 12, 26. 